\title{
Proteomic changes of the porcine small intestine in response to chronic heat stress
}

\author{
Yanjun Cui and Xianhong Gu \\ State Key Laboratory of Animal Nutrition, Institute of Animal Sciences, Chinese Academy of Agricultural Science, \\ Beijing 100193, People's Republic of China
}

Correspondence

should be addressed

to X Gu

Email

guxianhong@vip.sina.com

\begin{abstract}
Acute heat stress (HS) negatively affects intestinal integrity and barrier function. In contrast, chronic mild HS poses a distinct challenge to animals. Therefore, this study integrates biochemical, histological and proteomic approaches to investigate the effects of chronic HS on the intestine in finishing pigs. Castrated male crossbreeds $(79.00 \pm 1.50 \mathrm{~kg} \mathrm{BW})$ were subjected to either thermal neutral (TN, $21{ }^{\circ} \mathrm{C} ; 55 \% \pm 5 \%$ humidity; $\left.n=8\right)$ or HS conditions $\left(30{ }^{\circ} \mathrm{C} ; 55 \% \pm 5 \%\right.$ humidity; $n=8$ ) for 3 weeks. The pigs were sacrificed after 3 weeks of high environmental exposure and the plasma hormones, the intestinal morphology, integrity, and protein profiles of the jejunum mucosa were determined. Chronic HS reduced the free triiodothyronine $\left(\mathrm{FT}_{3}\right)$ and $\mathrm{GH}$ levels. HS damaged intestinal morphology, increased plasma D-lactate concentrations and decreased alkaline phosphatase activity of intestinal mucosa. Proteome analysis of the jejunum mucosa was conducted by 2D gel electrophoresis and mass spectrometry. Fifty-three intestinal proteins were found to be differentially abundant, 18 of which were related to cell structure and motility, and their changes in abundance could comprise intestinal integrity and function. The down-regulation of proteins involved in tricarboxylic acid cycle (TCA cycle), electron transport chain (ETC), and oxidative phosphorylation suggested that chronic HS impaired energy metabolism and thus induced oxidative stress. Moreover, the changes of ten proteins in abundance related to stress response and defense indicated pigs mediated long-term heat exposure and counteracted its negative effects of heat exposure. These findings have important implications for understanding the effect of chronic HS on intestines.
\end{abstract}
Key Words
- heat stress
- intestine function
- morphology
- proteomic
- pig (Sus scrofa)

Journal of Molecular Endocrinology

(2015) 55, 277-293

\section{Introduction}

Increasing global warming has resulted in increased research on the detrimental effects of heat stress (HS) on animal welfare and livestock production (Laganá et al. 2007, Yu et al. 2010). Pigs experience HS when ambient temperatures exceed their thermal neutral (TN) zone (16-22 ${ }^{\circ} \mathrm{C}$ for growing-finishing pigs) (Coffey et al. 1995). Compared with other species, finishing pigs are more susceptible to HS owing to their high metabolic heat production, quick fat deposition and lack of sweat glands (Dallaire et al. 1996). HS in pigs reduces food intake, body weight (BW) gain and meat quality, all of which potentially cause large economic losses (Pearce et al. 2012, Pearce et al. 2013a, Cruzen et al. 2015). For instance, HS has been estimated to cost the US swine 
industry losses of more than $\$ 300$ million annually (St-Pierre et al. 2003).

The gastrointestinal tract performs the critical function of selectively absorbing nutrients and water (Pearce et al. 2014b), and acts as a defensive barrier against endogenous and dietary pathogens as well as toxic compounds (Hirata et al. 2007). Gastrointestinal changes in these functions and integrity could be detrimental to health, performance and welfare of mammals. Therefore, intestinal health is of great importance in both human medicine and animal production. The gastrointestinal tract is highly sensitive to heat loads (Kregel 2002). Previous studies have shown that acute HS compromises the pig gastrointestinal tract epithelium and increases intestinal permeability to endotoxins such as lipopolysaccharide (LPS) (Pearce et al. 2013b), leading to low animal yield and performance, and increased morbidity and mortality (Liu et al. 2009). Moreover, investigations have been focused on mechanisms underlying the effect of acute HS on intestinal function and integrity. Acute HS causes hypoxia and inflammation of the intestinal epithelium (Lambert 2009, Qi et al. 2011), both of which regulate intestinal tight junction (TJ) proteins including the myosin light chains (MLC), occluding, claudin, and MLC kinase (MLCK) (Turner 2006, Pearce et al. 2013b), which maintain intestinal function and integrity. In addition, HS reduces the thyroid hormone (triiodothyronine $\left(T_{3}\right)$ ) level (Silva 2003), leading to the downregulation of intestinal alkaline phosphatase (AP) in transcriptional level and thus influencing intestinal function (Hodin et al. 1992). Acute HS also affects the intestine at the molecular level, including changes in gene and protein expression, and biochemical adaptations. For example, the investigation reported by $\mathrm{Yu}$ et al. (2010) demonstrated that acute HS could increase HSP27, HSP70 and HSP90 expression and trigger MAPK signaling pathways in the pig jejunum after 3 days of HS. Another similar study demonstrated that acute HS resulted in increased HSP 70 mRNA and protein abundance (Pearce et al. 2014a).

Interestingly, the majority of these studies have analyzed acute HS impact on the performance, physiology and molecular response of pig. In contrast to acute HS $\left(40-42{ }^{\circ} \mathrm{C}\right.$, less than $\left.24 \mathrm{~h}\right)$, chronic HS $\left(33-35^{\circ} \mathrm{C}\right.$, more than $24 \mathrm{~h}$ ) poses a distinct challenge to animals. Compared to hyperthermia and even death caused by acute HS, chronic HS can be tolerated for a longer period of time (weeks) (Horowitz, 2002). Nevertheless, the phenotypic changes that were reported in response to chronic HS in a variety of species including finishing pigs (Gordon 1993,
Hao et al. 2014) suggest that chronic mild HS alters animal performances and physiology. Response to HS is a complex biological process that involves many proteins. In contrast to conventional biochemical approaches that address one or a few specific proteins at a time, proteomics technologies facilitate the analysis of thousands of proteins, offering powerful tools for comprehensively assessing molecular alterations of intestines due to heat exposure. Molecular mechanisms underlying the effects of chronic HS in the intestine of finishing pigs have not been extensively studied. We hypothesized that changes of intestinal proteome would mediate the effects of HS on intestinal integrity, function and metabolism in finishing pigs.

Thus, this study aimed to investigate the proteomic response of the small intestine to chronic HS in finishing pigs and to identify novel intestinal protein profiles that could explain how pigs mediate and manage long-term heat exposure.

\section{Materials and methods}

\section{Animals and experimental design}

Sixteen castrated male DLY (crossbreeds of Landrace $X$ Yorkshire sows and Duroc boars) pigs were randomly selected from 8 litters from a pig breeding farm (Beijing, China), and were transported to the State Key Laboratory of Animal Nutrition (Beijing, China). Individual pig BWs were $79.00 \pm 1.50 \mathrm{~kg}$. Pigs were randomly allocated to either the control or heat-treated group (eight pigs per treatment group). The initial BW and litter origin of all pigs in each group was noted. Four pigs from one group were housed in an artificial climate chamber $\left(2.1 \times 4.8 \mathrm{~m}^{2}\right.$, luminance $100 \mathrm{l} \times$, photoperiod $14 \mathrm{~h}$ light, humidity $55 \% \pm 5 \%$ ), with four artificial climate chambers being used. All animals were fed with standard feed according to the NRC (1998) recommendations. The feed contained no antibiotics (Table 1).

Before the experiment, the animals were allowed to acclimate to the artificial climate chamber at $22^{\circ} \mathrm{C}$ for 7 days. Sixteen pigs were then randomly assigned to the two treatments. One group of eight pigs was housed in TN conditions $\left(22^{\circ} \mathrm{C}\right)$ with ad libitum feed intake. The remaining eight pigs were subjected to $\mathrm{HS}\left(30^{\circ} \mathrm{C}\right)$ with ad libitum feed intake. To minimize damage caused by acute high temperature $\left(30^{\circ} \mathrm{C}\right)$ in the HS group, the artificial temperature climate of the chamber was gradually increased and kept at $27^{\circ} \mathrm{C}$ on $\mathrm{d} 1$, and then raised to $28^{\circ} \mathrm{C}$ on $\mathrm{d} 2$. Thereafter, the temperature was kept

Published by Bioscientifica Ltd. 
Table 1 Composition of the experimental diet

\begin{tabular}{|c|c|}
\hline & $\mathbf{g} / \mathbf{k g}$ \\
\hline \multicolumn{2}{|l|}{ Ingredient } \\
\hline Corn & 662.0 \\
\hline Soybean meal, $42.8 \% \mathrm{CP}$ & 200.0 \\
\hline Wheat bran & 65.0 \\
\hline Wheat middlings & 40.0 \\
\hline Limestone & 10.0 \\
\hline Dicalcium phosphate & 6.0 \\
\hline Salt & 4.0 \\
\hline Premix ${ }^{a}$ & 10.0 \\
\hline L-Lysine $\cdot \mathrm{HCl}$ & 3.0 \\
\hline \multicolumn{2}{|l|}{ Chemical composition ${ }^{b}$} \\
\hline Digestive energy (MJ/kg) & 13.39 \\
\hline Crude protein & 157.3 \\
\hline Calcium & 6.5 \\
\hline Total phosphorus & 4.1 \\
\hline Available phosphorus & 1.7 \\
\hline Lysine & 9.2 \\
\hline Met + Cys & 5.4 \\
\hline
\end{tabular}

aPremix provided the following per $\mathrm{kg}$ of complete diet for finisher pigs: vitamin $A, 2512 \mathrm{IU}$; vitamin $\mathrm{D}_{3}, 1200 \mathrm{IU}$; vitamin $\mathrm{E}, 34 \mathrm{IU}$; vitamin $\mathrm{K}_{3}, 1.5 \mathrm{mg}$; vitamin $B_{12}, 17.6 \mu \mathrm{g}$; riboflavin, $2.5 \mathrm{mg}$; pantothenic acid, $6.8 \mathrm{mg}$; niacin, $20.3 \mathrm{mg}$; choline chloride, $351 \mathrm{mg} ; \mathrm{Mn}, 10 \mathrm{mg} ; \mathrm{Fe}, 50 \mathrm{mg}$; Zn, $50 \mathrm{mg}$; $\mathrm{Cu}$, $10 \mathrm{mg} ; \mathrm{l}, 0.3 \mathrm{mg} ; \mathrm{Se}, 0.3 \mathrm{mg}$.

${ }^{b}$ Calculated values.

constant at $30^{\circ} \mathrm{C}$, while control animals were maintained at $22^{\circ} \mathrm{C}$, until the end of the experiment. The experimental period lasted for 3 weeks.

The study was conducted at the State Key Laboratory of Animal Nutrition. The experiment was performed in accordance with guidelines of the Beijing Animal Ethics Committee and received prior approval from the Chinese Academy of Agricultural Sciences Animal Care and Use Committee.

\section{Blood and tissue collection}

Prior to sacrifice, venous blood was immediately collected from the jugular vein using venipuncture and centrifuged at 1500 gat $4{ }^{\circ} \mathrm{C}$ for 10 min to obtain $\mathrm{K}_{2}$ EDTA plasma. The plasma were subsequently transferred into $1.5 \mathrm{ml}$ sterile tubes and stored at $-20^{\circ} \mathrm{C}$ until later assay. Thereafter, the pigs were slaughtered using a head-only electric stun tong apparatus (Xingye Butchery Machinery Co. Ltd, Changde, Hunan Province, China).

Intestinal tissues were obtained immediately following exsanguination euthanasia. The intestinal sections were quickly divided into the duodenum $(5 \mathrm{~cm}$ from the pylorus), and jejunum $(150 \mathrm{~cm}$ anterior to the ileocecal valve) and the ileum $(150 \mathrm{~cm}$ proximal from the ileal-cecal junction). The jejunum was selected and thoroughly rinsed with physiological saline then cut into
$1 \mathrm{~cm}$ length segments. It was fixed in $10 \%$ neutral formalin then used for histological analysis. Mucosa from the remaining segment was obtained as described previously (Wang et al. 2007) and snap frozen in liquid nitrogen then stored at $-80^{\circ} \mathrm{C}$ until biochemical and molecular analyses. Jejunum tissue from the small intestine was selected for analysis, as this tissue is important for nutrient absorption, high blood flow, and sensitivity to hypoxia and inflammation (Maier et al. 2009).

\section{Quantification for plasma thyroid hormones and growth hormone}

Plasma $T_{3}$, free $T_{3}\left(F_{3}\right)$, thyroxine $\left(T_{4}\right)$, free thyroxine $\left(\mathrm{FT}_{4}\right)$, and growth hormone (GH) were quantified by RIA, using standard RIA kits (Huaying Bio-Tech Research Institute, Beijing, China). The intra-assay coefficient of variation was $<5 \%$. Plasma levels of $\mathrm{T}_{3}, \mathrm{FT}_{3}, \mathrm{~T}_{4}$ and $\mathrm{GH}$ are expressed as $\mathrm{ng} / \mathrm{ml}$ of serum, $\mathrm{FT}_{4}$ as $\mathrm{pg} / \mathrm{ml}$.

\section{Intestinal morphology assessment}

The intestinal samples fixed in formalin were sent to the State Key Laboratory of Animal Nutrition, Institute of Animal Sciences. Jejunum sections were embedded in paraffin and transversely sectioned in $(5 \mu \mathrm{m}$ thick) and stained with hematoxylin and eosin following deparaffinization and dehydration. Intestinal tissues and structures were observed using a $\mathrm{BH} 2$ Olympus microscope (Olympus, Tokyo, Japan) and analyzed using an image analysis system (Olympus 6.0). Villi height, crypt depth and their ratios were assessed following the method of Gabler et al. (2007).

\section{Intestinal integrity and function assay}

Plasma D-lactate concentration was measured using a porcine-specific ELISA according to the manufacturer's instructions (Beijing Chemclin Biotech Co., Ltd, Beijing, China). The intra-assay coefficient of variation was $<5 \%$. Plasma D-lactate level is expressed as $\mu \mathrm{g} / \mathrm{ml}$ of plasma.

AP activity of jejunum mucosal was determined by a kinetic based assay using a commercially available kit (Nanjing Jiancheng Co., Ltd, Nanjing, China). Protein was extracted from the jejunum mucosal and protein concentration was determined using bovine serum albumin (fraction $\mathrm{V}$ ) as the protein standard. AP activity of jejunum mucosal are expressed as $\mu / g$ protein. The intra-assay coefficient of variation was $<5 \%$.

Published by Bioscientifica Ltd 


\section{Proteomic analysis}

Jejunum mucosa protein extraction Total proteins were extracted from jejunum mucosal scrapings by following an existing procedure with slight modifications (Wang et al. 2009). In brief, frozen samples of jejunum mucosal scrapings from all pigs in two groups were crushed in a mortar containing liquid nitrogen. The powder (approximately $100 \mathrm{mg}$ per sample) was transferred to sterile tubes with lysis buffer (LB; containing $7 \mathrm{M}$ urea, $2 \mathrm{M}$ thiourea, $4 \% \mathrm{w} / \mathrm{v}$ CHAPS, $1 \% \mathrm{w} / \mathrm{v}$ DTT, $1 \% \mathrm{v} / \mathrm{v}$ IPG Buffer pH 4-7, 1\% v/v proteinase inhibitor cocktail). The mixture was sonicated in an ice bath using a Model VCX 500 Ultrasonicater (Sonics \& Materials, Newtown, CT, USA) at $20 \%$ power output for $10 \mathrm{~min}$ with 2 -s on and 4-s off cycles. Subsequently, the lysed cell suspension was incubated at room temperature for $1 \mathrm{~h}$ to solubilize proteins. After centrifugation at $40000 \boldsymbol{g}$ and $4{ }^{\circ} \mathrm{C}$ for $40 \mathrm{~min}$, the supernatant protein was collected and its protein concentration was determined according to a modified Bradford assay (Ramagli \& Rodriguez 1985). The protein concentration was $6.84 \pm 0.42 \mathrm{mg} / \mathrm{ml}$.

2D gel electrophoresis A $1 \mathrm{mg}$ protein sample was loaded on a $24 \mathrm{~cm}$ IPG strip (immobilized $\mathrm{pH}$ gradient, pH 4-7, linear, GE Healthcare) (Amersham Bioscience, Uppsala, Sweden). Each protein sample was assessed in triplicate. Isoelectric focusing (IEF) was carried out at $20^{\circ} \mathrm{C}$ for $14 \mathrm{~h}$ at $30 \mathrm{~V}, 2 \mathrm{~h}$ at $200 \mathrm{~V}, 0.5 \mathrm{~h}$ at $500 \mathrm{~V}, 1 \mathrm{~h}$ at $1000 \mathrm{~V}$, $3 \mathrm{~h}$ at $8000 \mathrm{~V}$, and then held at $8000 \mathrm{~V}$ until a total of at least $60000 \mathrm{Vh}$ was reached (Ettan IPGphorII, GE Healthcare, Uppsala, Sweden). Focused IPG strips were equilibrated for $15 \mathrm{~min}$ in equilibration buffer (6 M urea, $30 \%$ glycerol, 2\% SDS, $50 \mathrm{mM}$ Tris pH 8.8, 1\% DTT) under gentle agitation, and then for an additional $15 \mathrm{~min}$ in the same buffer, except that DTT was substituted with $2.5 \%$ iodoacetamide. After equilibration, the strips were transferred to vertical slab gels (12\% SDS-PAGE) for second-dimensional electrophoresis with the Ettan DALT six gel system (GE Healthcare).

Image acquisition and analysis Gels were fixed for about $8 \mathrm{~h}$ in a solution containing (10\% (v/v) acetic acid, $40 \%(\mathrm{v} / \mathrm{v})$ ethanol, and 50\% (v/v) water), washed three times in water, and then stained with Coomassie colloidal blue G-250 according to the GE handbook (GE Healthcare) with minor modifications. Gel images were acquired with the PowerLook 2100XL color scanner (UMAX Technologies, Atlanta, CA, USA) at a resolution of 16 bits and $300 \mathrm{dpi}$, and were assayed by Image master 2D Platinum
Software Version 6.0 (GE Healthcare). To limit experimental variation among $2 \mathrm{D}$ gels, quantitative comparison of protein spots was performed on the base of their percentage volumes. All automatic spot detections for each gel were manually inspected and edited as necessary to confirm the absence of mismatched and unmatched spots. One-way ANOVA and comparison of treatment means were carried out on the SAS program. Differentially expressed protein spots were (1) consistently present in all replicates and (2) changed abundance by at least \pm 1 .2fold, with an error probability of $P \leq 0.05$.

\section{Protein identification}

The MALDI-TOF-MS/MS analysis was based on the method previously described (Xiong et al. 2011). Selected spots were excised from the gels and destained using a $20 \%$ $\mathrm{w} / \mathrm{v}$ sodium thiosulfate and $1 \% \mathrm{w} / \mathrm{v}$ potassium ferricyanide for $5 \mathrm{~min}$. The supernatant was removed and the gel spots were washed twice with $25 \mathrm{mM}$ ammonium bicarbonate in 50\% v/v ACN for $20 \mathrm{~min}$. The gel spots were then washed in ACN, dried in a Speed-Vac and digested with $20 \mathrm{mg} / \mathrm{ml}$ of trypsin in $25 \mathrm{mM}$ ammonium bicarbonate for $12 \mathrm{~h}$ at $37^{\circ} \mathrm{C}$. Tryptic peptides were passed through C18 Zip-Tips and mixed with $5 \mathrm{mg} / \mathrm{ml}$ of an R-cyano-4-hydroxycinnamic acid as matrix and subjected to MALDI-TOF/TOF analysis (4700 Proteomics Analyzer, Applied Biosystems). For database searching, data files obtained from MALDI-TOF/TOF mass spectra were submitted to the MASCOT search engine using Daemon 2.1.0 (Matrix Science; http://www.matrixscience.com) on a MASCOT server version 2.2.1. The data were searched against the NCBInr database. The peptides were constrained to be tryptic with a maximum of one missed cleavage. Carbamidomethylation of cysteine was considered a fixed modification, and oxidation of methionine residues was considered as a variable modification. Protein identifications were accepted if they established a probability $>95 \%$ and contained at least two identified peptides having maximal peptide coverage.

\section{Bioinformatic approach}

To enrich the differentially expressed proteins with respect to specific functional terms, the protein lists were analyzed using the plug-in of the Cytoscape software: ClueGO (http://www.ici.upmc.fr/cluego/) (Saito et al. 2012) with the Gene Ontology database (release date: June 2014). The ontology selection on the base of biological processes and enrichment analysis was performed by the right-side

Published by Bioscientifica Ltd 
hyper-geometric statistic test and its probability value was corrected by the Bonferroni's method (Bindea et al. 2009). A pathway enrichment analysis of the differentially expressed proteins (Ashburner et al. 2000) was conducted using ClueGO software and applying database from the Kyoto Encyclopedia of Genes and Genomes (KEGG) database (release date: March 2014).

A protein interaction network of the differentially regulated proteins was analyzed using the online database resource Search Tool for the Retrieval of Interacting Genes (STRING 9.1) (Szklarczyk et al. 2011). The protein regulation networks and protein interaction maps are in the Sus scrofa molecular networks database. The network nodes are the proteins, and the edges represent the predicted functional associations. An edge may be drawn with up to seven differently colored lines. These lines represent the existence of the seven types of evidence used for predicting the associations. The interactions between the imported proteins and all proteins stored in the database were then identified.

\section{Validation of differentially expressed proteins by Western blot}

Western-blotting analysis was used to validate the main differentially expressed proteins. Total protein (30 $\mu \mathrm{g} / \mathrm{sample}$ ) was separated by electrophoresis (Bio-Rad) on $10 \%$ SDS-PAGE, and transferred to a PVDF membrane (Millipore, Billerica, MA, USA). The blotted membrane was blocked for $2 \mathrm{~h}$ at room temperature in $1 \times$ TBST $(0.05 \%$ Tween 20, $100 \mathrm{mM}$ Tris- $\mathrm{HCl}$ and $150 \mathrm{mM} \mathrm{NaCl}(\mathrm{pH}$ 7.5)) containing 5\% fat-free dry milk, and then incubated under gentle agitation overnight at room temperature in the presence of the primary antibodies: heat shock protein $105 \mathrm{kDa}$ (HSPH1; spot 6), 1:5000 dilution of purified mouse monoclonal anti-HSPH1 antibody (Abcam, AB109624 Cambridge, MA, USA); heat shock $70 \mathrm{kDa}$ protein 1B (HSPA1A; spot 7), 1:5000 dilution of purified mouse monoclonal anti-HSPA1A antibody (TDY062F, Beijing Biosynthesis Biotechnology Co., Ltd, Beijing, China); glyceraldehyde-3-phophate dehydrogenase (GAPDH), 1:2000 dilution of purified mouse monoclonal anti-GAPDH antibody (TDY062, Beijing Biosynthesis Biotechnology Co., Ltd); hsp27(HSPB1; spot 86), 1:1000 dilution of purified rabbit polyclonal anti-HSPB1 protein antibody (Abcam, AB2790), which could bind to their specific protein. The blots were extensively washed with TBST buffer for $10 \mathrm{~min} \times 3$ times and incubated under gentle agitation with the secondary antibodies for immunodetection. The antigen-antibody interaction was

carried out for $1 \mathrm{~h}$, and the cross-reacting proteins were detected using ECL (Perkin Elmer Life Sciences, Boston, MA, USA). The protein bands were visualized with a chemiluminescence substrate using a gel-imaging system (Tanon Science and Technology, Shanghai, China) with Image Analysis Software (National Institutes of Health, Bethesda, MD, USA). In all instances, density values of bands were corrected by subtraction of the background values. GAPDH was used as the internal reference protein. Bands were standardized to the density of GAPDH and normalized fold expression represented as a ratio of each protein to GAPDH.

\section{Statistical analysis}

Statistical analyses were conducted using SAS version 8.2 software (SAS Institute, Cary, NC, USA). Data were expressed as mean \pm s.D. The Student's $t$-test was used for statistical analysis and a difference at $P \leq 0.05$ was considered statistically significant.

\section{Results}

\section{Effect of chronic HS on plasma hormone}

The comparison of levels in heat exposure pigs and control are shown in Table 2. As compared to the control group, the levels of plasma $\mathrm{FT}_{3}$ and $\mathrm{GH}$ were significantly decreased $(P=0.008$ and $P=0.015$ respectively), while the level of $\mathrm{T}_{3}, \mathrm{~T}_{4}$ and $\mathrm{FT}_{4}$ were not changed $(P>0.05)$.

\section{Effect of chronic HS on jejunum morphology, integrity and function}

Chronic HS resulted in morphological alterations of the porcine small intestine. Desquamation was prevalent at

Table 2 Effect of chronic heat stress on plasma hormone. Pigs were exposed to either thermal neutral (TN) conditions $\left(22^{\circ} \mathrm{C}\right)$ or chronic heat stress $(\mathrm{HS})$ conditions $\left(30^{\circ} \mathrm{C}\right)$ for 3 weeks. Values represent the mean \pm s.D., $n=8$ pigs for each group

\section{Parameter}

$\mathrm{T}_{3}(\mathrm{ng} / \mathrm{ml})$

$\mathrm{FT}_{3}(\mathrm{ng} / \mathrm{ml})$

$\mathrm{T}_{4}(\mathrm{ng} / \mathrm{ml})$

$\mathrm{FT}_{4}(\mathrm{pg} / \mathrm{ml})$

$\mathrm{GH}(\mathrm{ng} / \mathrm{ml})$

\begin{tabular}{r}
\multicolumn{1}{c}{ TN } \\
\hline $0.87 \pm 0.11$ \\
$3.14 \pm 0.14$ \\
$72.71 \pm 2.07$ \\
$10.48 \pm 0.31$ \\
$5.06 \pm 0.16$
\end{tabular}

${ }^{*} P \leq 0.05$ and ${ }^{\dagger} P \leq 0.01$ before vs after heat stress. $T_{3}$ (triiodothyronine) $\mathrm{FT}_{3}$ (free triiodothyronine); $\mathrm{T}_{4}$ (thyroxine); $\mathrm{FT}_{4}$ (free thyroxine); $\mathrm{GH}$ (growth hormone). 
the tips of the intestinal villus in heat-stressed pigs as shown in Fig. 1. Compared with the TN group, HS reduced villus height and crypt depth $(P \leq 0.05$, Table 3$)$. There were no differences detected between TN and HS in terms of villus: crypt ratio ( $P>0.05$, Table 3$)$.

Plasma D-lactate concentrations were measured as a marker of intestine integrity. We demonstrated that concentrations of plasma D-lactate were increased 19.5\% due to HS $(P \leq 0.05)$. As expected, HS resulted in a $33 \%$ decrease in AP activity of jejunum mucosa $(P<0.05$, Table 4), a measure of intestine function.

\section{Proteomic alterations of jejunum mucosa in response to HS}

Finishing pigs were subjected to chronic HS $\left(30^{\circ} \mathrm{C}\right)$ and jejunum mucosa changes in the protein profiles were determined by a 2DE approach. A total of 992 protein spots were detected on 2D gels of jejunum mucosa and spot localization on the map is shown in Fig. 2. There were 53 differentially expressed proteins and their biochemical information is summarized in Table 5. Based on their biological functions, these proteins were classified into seven groups: i) stress response and defense system $(18.87 \%)$, ii) cell structure and motility (33.96\%), iii) glucose and energy metabolism (20.75\%), iv) antioxidant system $(3.77 \%), v)$ cellular apoptosis $(11.32 \%)$ vi) nutrient absorption and transport (5.66\%), and vii) gene regulation

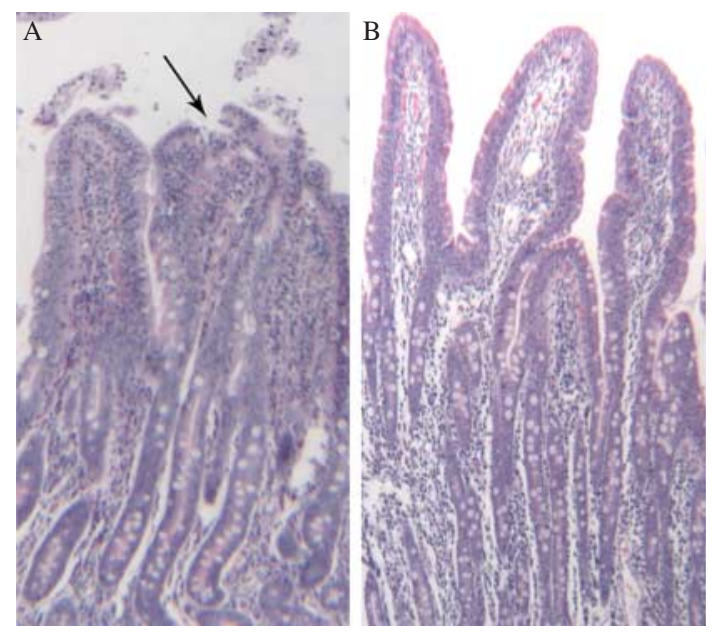

\section{Figure 1}

Photomicrographs of hematoxylin- and eosin-stained sections of the pig small intestine from heat treated and control animals after 3 weeks of treatment ( $200 \times$ magnification). ( $A$ and $B$ ) Heat treated jejunums and control respectively. Damage to the intestinal villi is obvious, with desquamation at the tips of the intestinal villi. Abnormal microstructures are indicated with arrowheads.
Table 3 The effect of constant heat stress on jejunum morphology. Pigs were exposed to either thermal neutral (TN) conditions $\left(22^{\circ} \mathrm{C}\right)$ or chronic heat stress (HS) conditions $\left(30^{\circ} \mathrm{C}\right)$ for 3 weeks. Values represent the mean \pm s.D., $n=8$ pigs for each group

\begin{tabular}{|c|c|c|c|}
\hline Parameter & TN & HS & $P$ value \\
\hline Villus height $(\mu \mathrm{m})$ & $533.37 \pm 17.20$ & $455.37 \pm 17.42 *$ & 0.02 \\
\hline Crypt depth $(\mu \mathrm{m})$ & $182.12 \pm 6.29$ & $161.62 \pm 7.78^{*}$ & 0.05 \\
\hline Villus:Crypt ratio & $2.95 \pm 0.10$ & $2.83 \pm 0.14$ & 0.59 \\
\hline
\end{tabular}

${ }^{*} P \leq 0.05$ before vs after heat stress.

(5.66\%) (Fig. 3). Those related to cell structure and motility, glucose and energy metabolism, stress response and defense were predominant and accounted for approximately $73 \%$ of the differential proteins. A comparison of differentially expressed proteins between the groups showed that fewer protein species were up-regulated in pigs subjected to chronic HS (19 vs 34) (Fig. 4). These 19 up-regulated protein species were distributed in five categories: seven in stress response and defense, seven in cell structure and motility, one in nutrient absorption and transport, two in cellular proliferation and apoptosis, and two in gene regulation. The 34 down-regulated protein species were distributed in seven categories: three in stress response and defense, 11 in cell structure and motility, 11 in glucose and energy metabolism, two in the antioxidant system, four in cellular proliferation and apoptosis, another two in nutrient absorption and transport, and one in gene regulation.

\section{Confirmation of differential proteins in abundance by Western blot}

Immunoblotting was further performed to verify the proteomic results. Confirmation of the three stressresponse marker proteins HSPH1 (spot 6), HSPA1A (spot 7) and HSPB1 (spot 86) was carried out using antibodies. The results of the immunoblotting analysis were consistent with the 2DE results (Fig. 5).

\section{Bioinformatics analysis of differentially expressed proteins}

Gene Ontology (GO) enrichment analysis and functional annotation are useful for the analysis of large proteomic and genomic datasets. Significantly overrepresented GO terms were examined to determine the putative biological events behind the data and provide a primary overview of the jejunum mucosa proteome. Functional enrichment

Published by Bioscientifica Ltd 
Table 4 Effects of heat stress on intestinal integrity and function. Pigs were exposed to either thermal neutral (TN) conditions $\left(22^{\circ} \mathrm{C}\right)$ or chronic heat stress (HS) conditions $\left(30^{\circ} \mathrm{C}\right)$ for 3 weeks. Values represent the mean \pm s.D., $n=8$ pigs for each group

\begin{tabular}{|c|c|c|c|}
\hline Parameter & TN & HS & $P$ value \\
\hline $\begin{array}{l}\text { AP }(\mu / \mathrm{g} \text { prot }) \\
\text { d- lactate }(\mu \mathrm{g} / \mathrm{ml})\end{array}$ & $\begin{array}{r}159.74 \pm 14.95 \\
0.866 \pm 0.026\end{array}$ & $\begin{array}{r}106.86 \pm 16.18^{*} \\
1.076 \pm 0.101^{*}\end{array}$ & $\begin{array}{l}0.008 \\
0.05\end{array}$ \\
\hline
\end{tabular}

${ }^{*} P \leq 0.05$ before vs after heat stress. $A P$, alkaline phosphatase.

analysis of all differential proteins was conducted using the ClueGo software. The result showed that two major functional groups were significantly enriched: cell structure and motility and energy metabolism (Fig. 6). Proteins that were enriched in the cell structure and motility included alpha-actinin-1 (ACTN1; spot 2), villin 1 (VIL1; spot 15), cofilin-1 (CFL1; spot 13), coronin-1B (CORO1B; spot 50) and ezrin (EZR; spot 52). NADH dehydrogenase (ubiquinone) 1 alpha subcomplex subunit 10 (NDUFA10; spot 33), NADH-coenzyme Q reductase (NDUFS3; spot 46), NADH-ubiquinone oxidoreductase $75 \mathrm{kDa}$ subunit (NDUFS1; spot 49), cytochrome b-c1 complex subunit 1, mitochondrial (UQCRC1; spot 56), stomatin-like protein 2, mitochondrial (STOML2; spot 37), ATP synthase subunit alpha, mitochondrial (ATP5A1; spot 39) and ATP synthase subunit beta, mitochondrial (ATP5B; spot 31) were significantly enriched in the energy metabolism.

KEGG pathway enrichment analysis of the differentially expressed proteins revealed protein functional information in the metabolic pathway. The pathway analysis showed that 11 differential proteins were significantly enriched in the two pathways that were involved in multiple biological processes containing oxidative phosphorylation and regulation of actin cytoskeleton (Table 6).

Proteins function as elementary parts of protein complexes in living cells. However, they do not act independently. Accordingly, 32 proteins were recognized as key nodes with various relationships in protein-protein interactions (PPI) (Fig. 7). Using the online tools of STRING 9.1, we demonstrated that 11 proteins were related to cell structure and motility: alpha-actinin-1 (ACTN1; spot 2), myosin regulatory light chain, LC20 (MYL9; spot 4), cardiac muscle alpha actin 1 (ACTC1; spot 18), villin 1 (VIL1; spot 15), desmin (DES; spot 76), cofilin-1 (CFL1; spot 13), peflin (PEF1; spot 3), synemin (SYNM; spot 12), non-muscle caldesmon (CALD1; spot 14), ezrin
(EZR; spot 52), and serine/threonine-protein phosphatase PP1-beta catalytic subunit (PPP1CB; spot 67 and 68). The second most represented group included proteins related to stress response and defense, and antioxidant systems: peptidyl-prolyl cis-trans isomerase (FKBP4; spot 5), heat shock protein $105 \mathrm{kDa}$ (HSPH1; spot 6), hsp27 (HSPB1; spot 86 ), heat shock $70 \mathrm{kDa}$ protein 5 (HSPA5; spot 32), heat shock $70 \mathrm{kDa}$ protein 1B (HSPA1A; spot 7), haptoglobin (HP; spot 1), retinol-binding protein 4 (RBP4; spot 24), serum albumin (ALB; spot 38), alpha-2-HS-glycoprotein (AHSG; spot 74), and glutathione S-transferase mu 2 (GSTM2; spot 16). In contrast, proteins involved in glucose and energy metabolism ranked as the third most represented, each linked to the network through nine proteins: phosphoglucomutase 2 (PGM2; spot 26), Malate dehydrogenase (MDH2; spot 51), NADH-coenzyme $Q$ reductase (NDUFS3; spot 46), NADH-ubiquinone oxidoreductase $75 \mathrm{kDa}$ subunit (NDUFS1; spot 49), cytochrome b-c1 complex subunit 1, mitochondrial (UQCRC1; spot 56), stomatin-like protein 2, mitochondrial (STOML2; spot 37), ATP synthase subunit alpha, mitochondrial (ATP5A1; spot 39) and ATP synthase subunit beta, mitochondrial (ATP5B; spot 31). In addition, three proteins were involved in cellular apoptosis: gelsolin (GSN; spot 8), CDC37 cell division cycle 37 protein (CDC37; spot 34), and Caspase-7 (CASP7; spot 70).

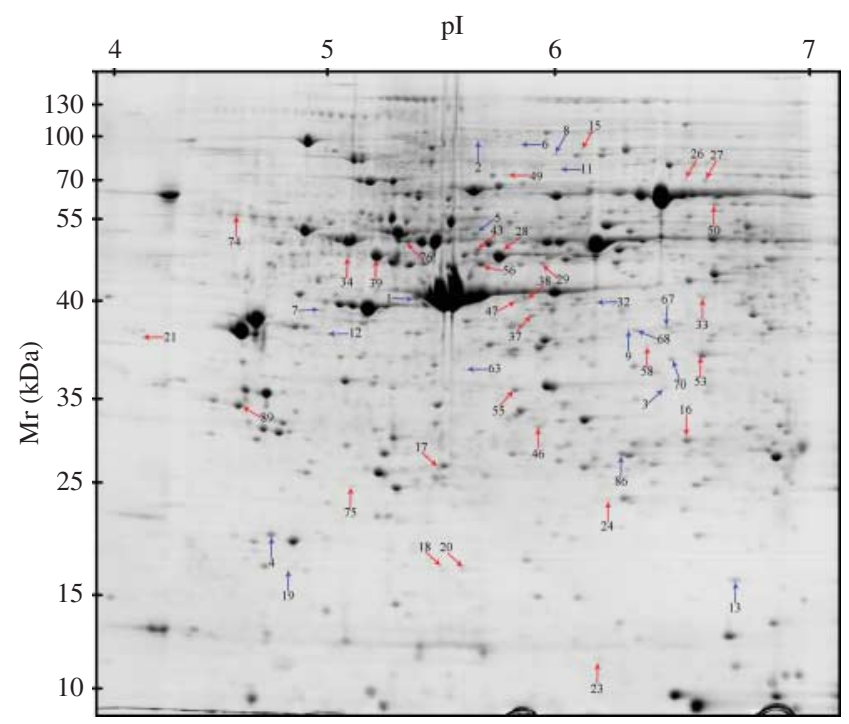

Figure 2

Protein profile patterns in the jejunum mucosa of finishing pigs. Protein spots showing significant differences (1.3-fold, $P \leq 0.05)$ were cut out and identified by MALDI-TOF/TOF MS. Protein spots of differential abundance with known identities are marked with color arrows, blue indicates up-regulated and red indicates down-regulated.

Published by Bioscientifica Ltd. 


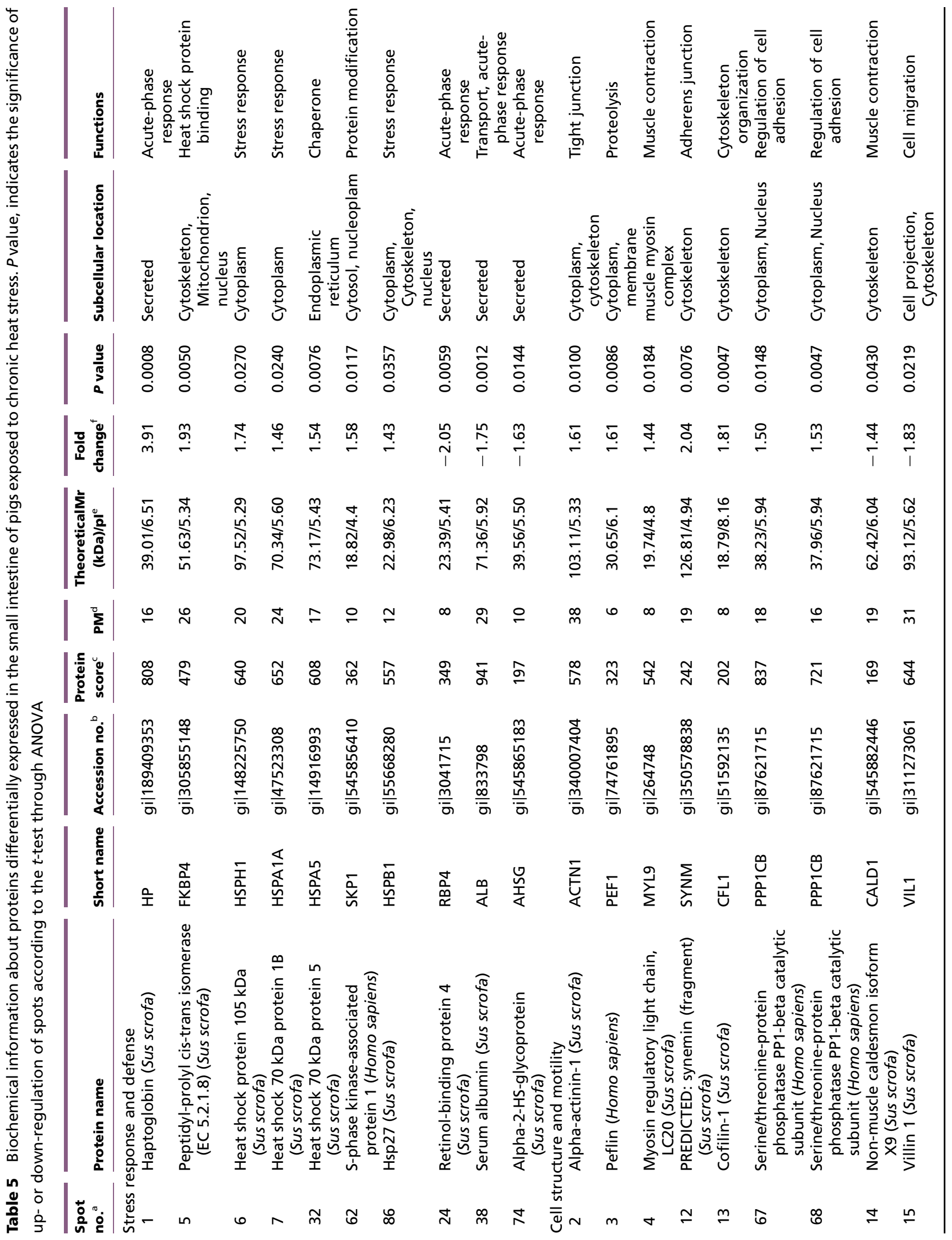



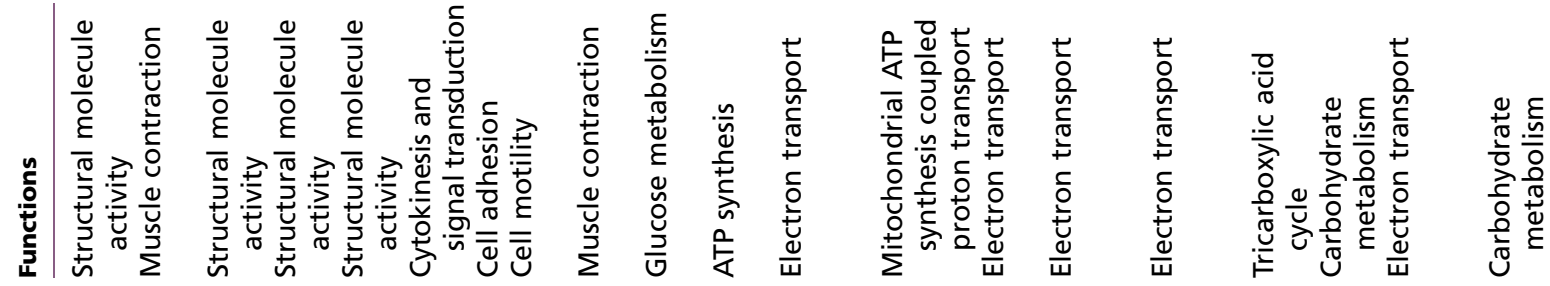

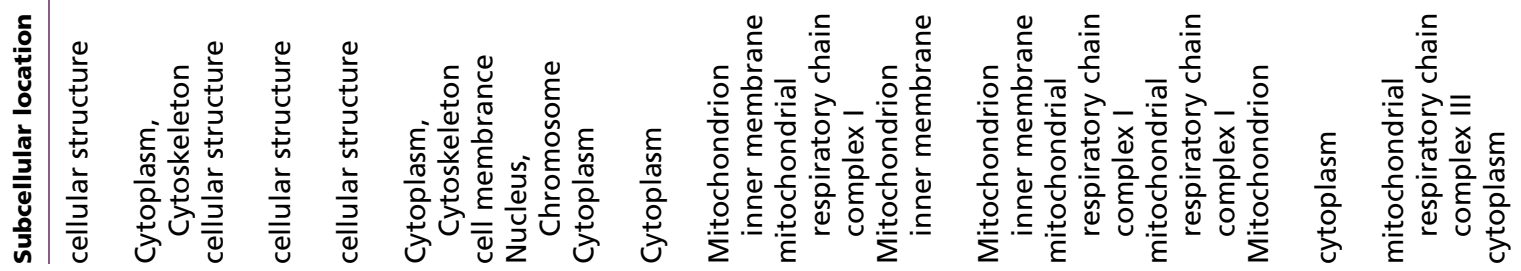

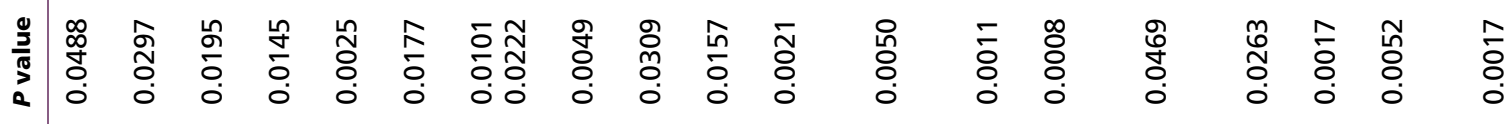

흥

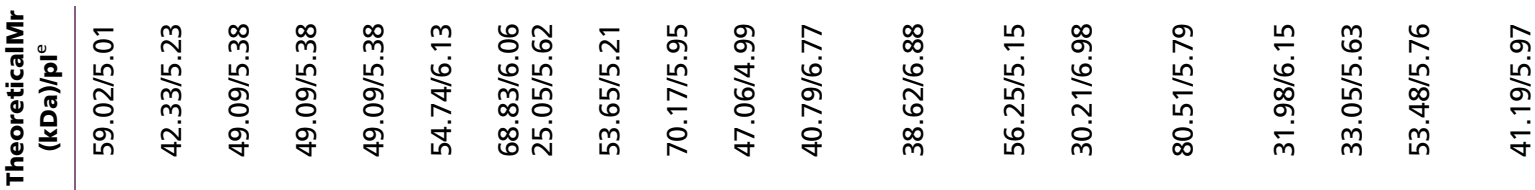

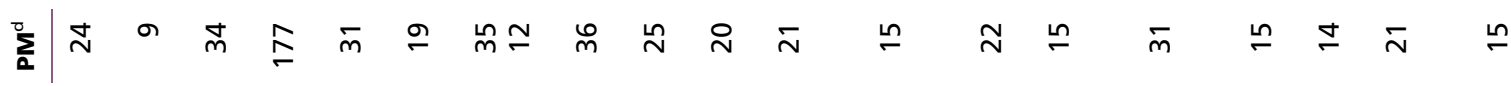

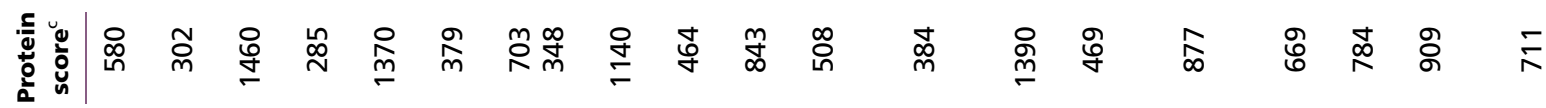

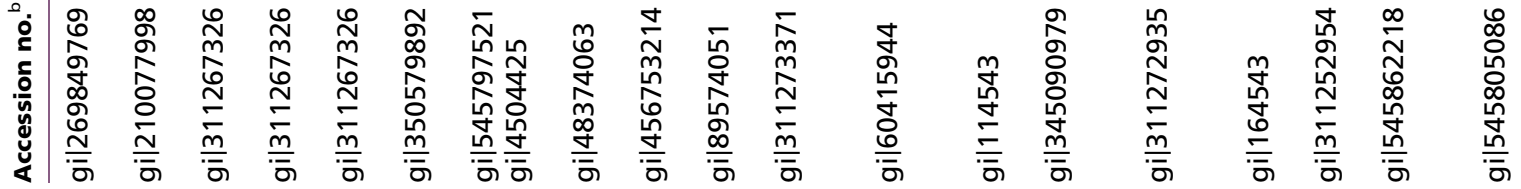

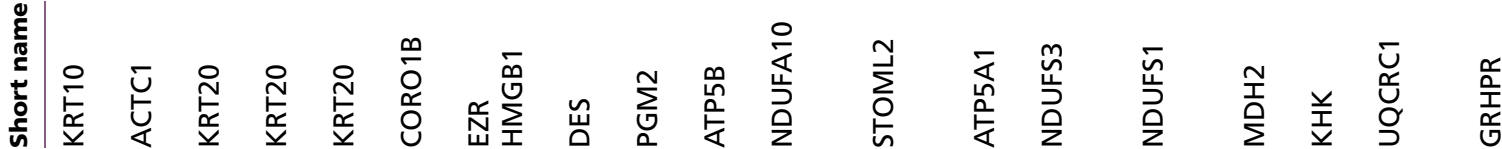

\section{$\widehat{N}$}

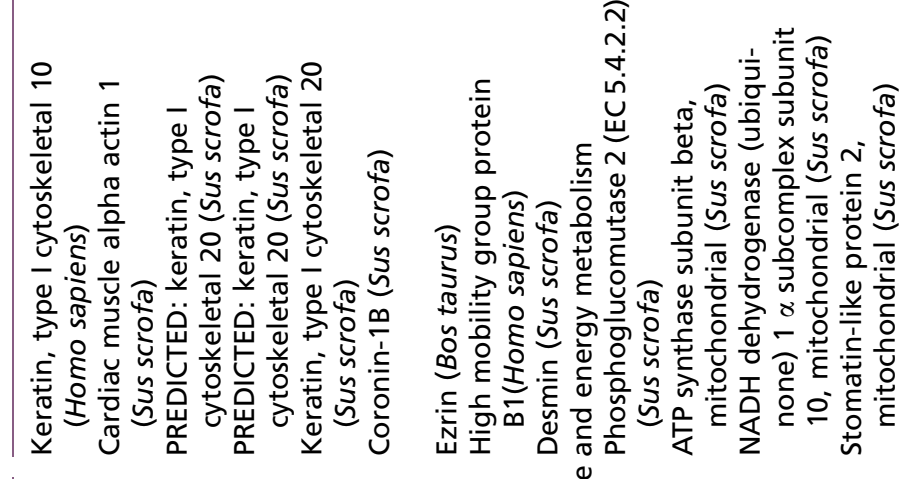

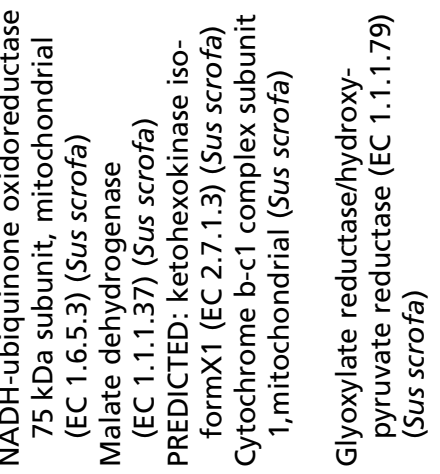

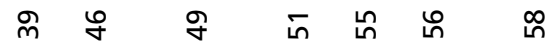




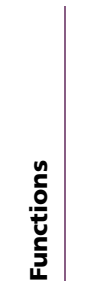

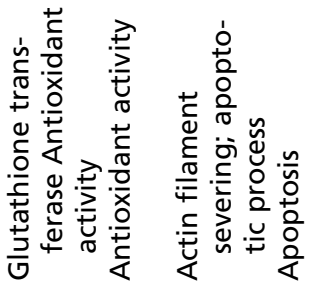

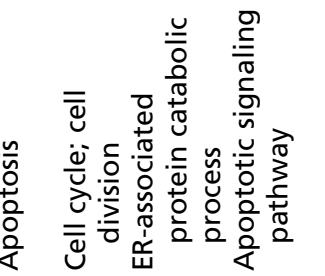

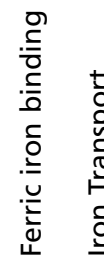

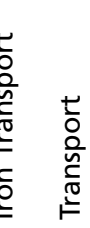

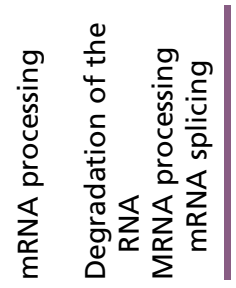

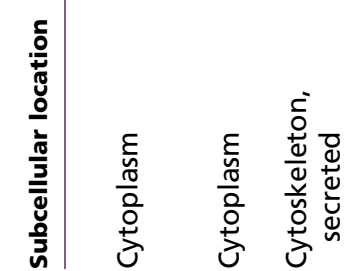<smiles>[CH]1[CH]C1</smiles>

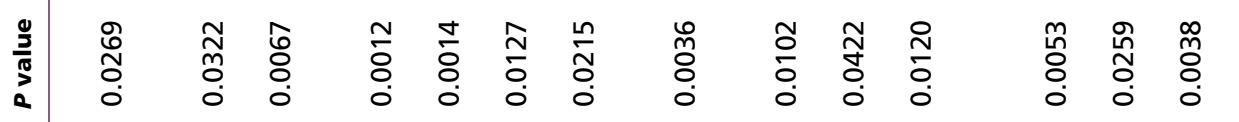

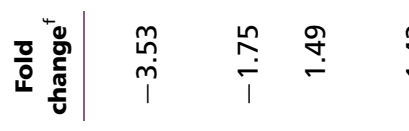

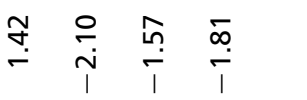

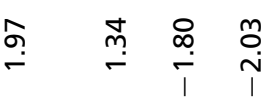

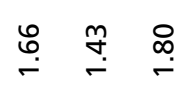

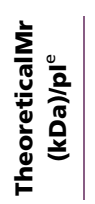

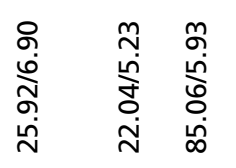

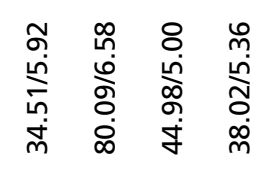

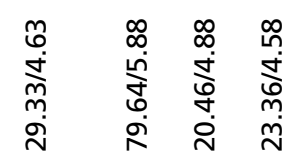

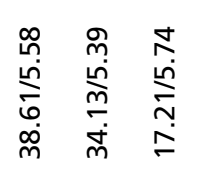

$\sum_{2}^{5}$

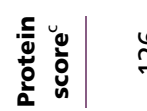

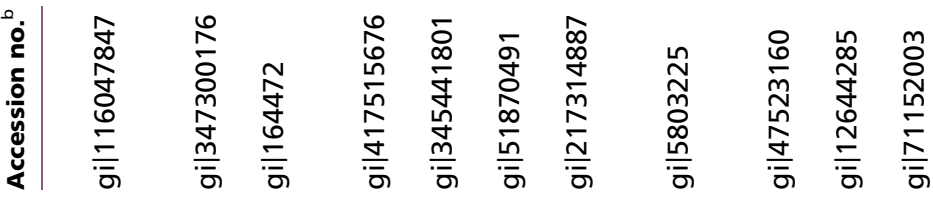

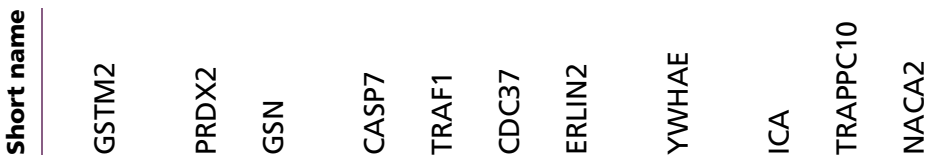

$\stackrel{ \pm}{ \pm}$

$\stackrel{2}{2}$

$\circ \infty$

$-\infty m$

용 임

\&̊ $\stackrel{m}{m} \stackrel{m}{m}$

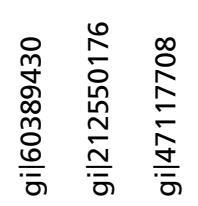

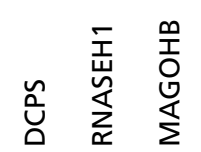

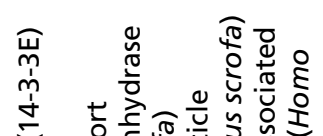

美

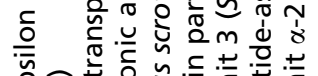

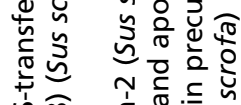

药

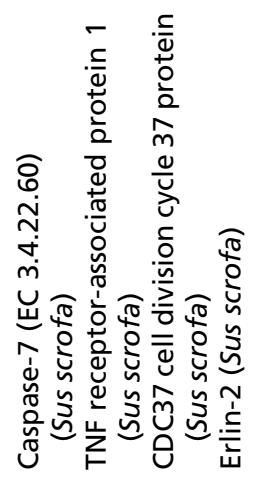

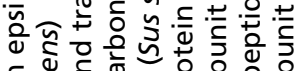

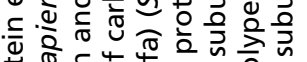

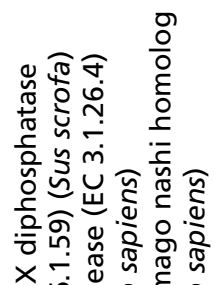

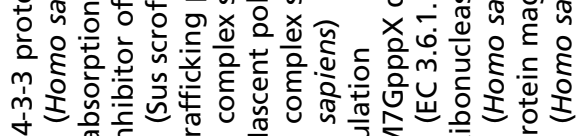

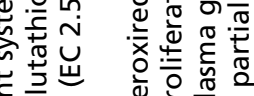

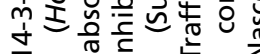

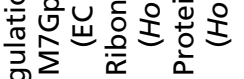

茎

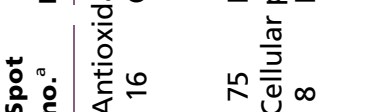

尺

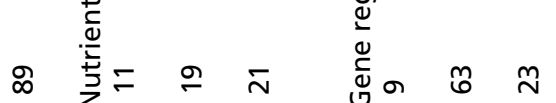

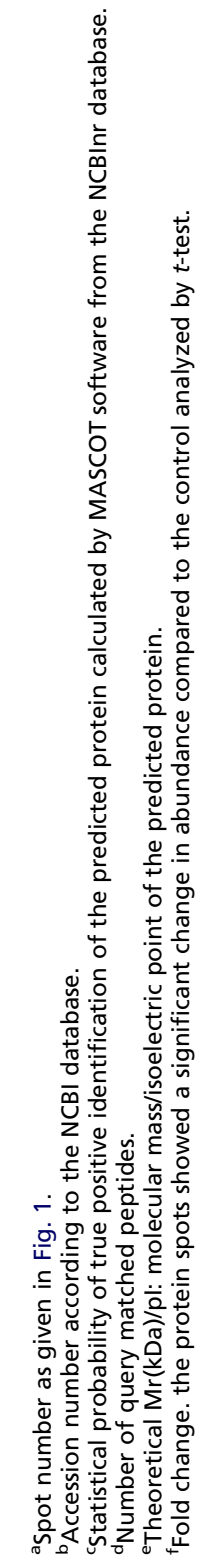




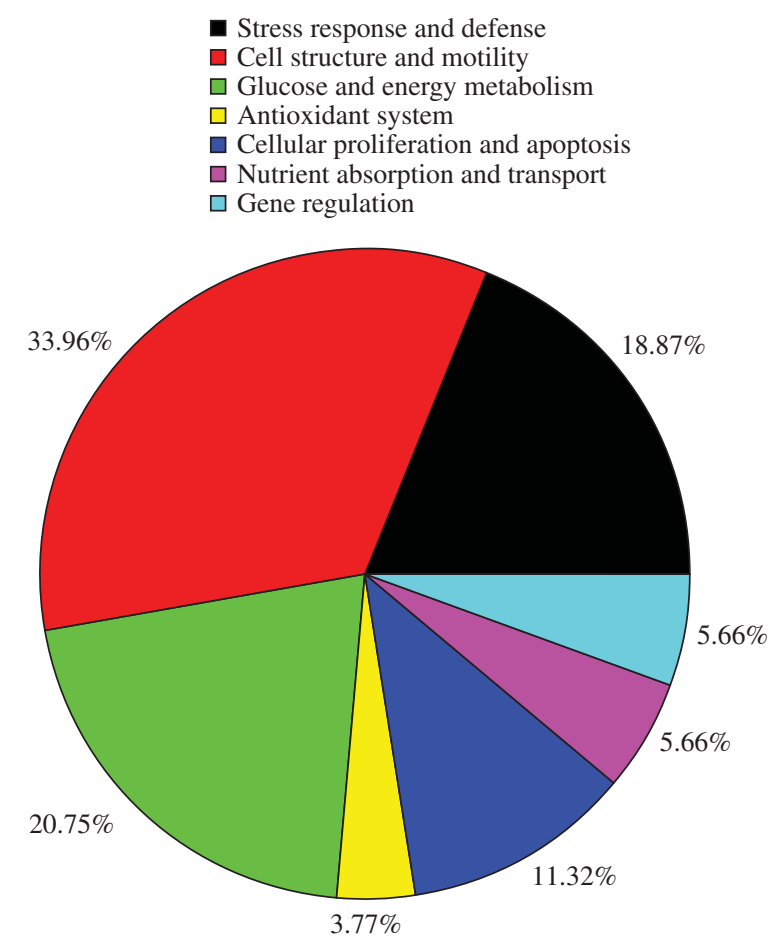

Figure 3

Functional classification of the differentially expressed proteins identified from the jejunum mucosa of finishing pigs. The color codes represent different protein functional groups.

\section{Discussion}

Our previous experiment (Hao et al. 2014) demonstrated that in finishing pigs chronic mild HS $\left(30^{\circ} \mathrm{C}\right.$ for 3 weeks) resulted in decreased feed intake, daily $\mathrm{BW}$ gain and increased rectal temperature, respiration rate and plasma cortisol. The alterations in these parameters, commonly considered indicators of the consequences of HS on animal physiology (Morera et al. 2012), indicated that our finishing pigs were under conditions of moderate hyperthermia. In order to survive in a high temperature environment, animals have developed specific responses to hyperthermia by regulating the endocrine systems. We observed that chronic HS lowered $\mathrm{FT}_{3}$ and $\mathrm{GH}$ in heatstressed pigs. This finding was in line with the results of similar HS experiments in Holstein cows and cattle (Mohammed \& Johnson 1985, Pereira et al. 2008). The decline in thyroid hormones along with decreased plasma growth hormone $(\mathrm{GH})$ level has a synergistic effect to reduce heat production.

HS leads to increased intestinal permeability in various mammalian species (Barthe et al. 1998, Lambert et al. 2002), facilitating the passive non-mediated diffusion of both small (e.g. D-lactate) and large molecules (e.g. lipopolysaccharide, LPS) from the gastrointestinal lumen to the blood. In the current experiment blood D-lactate concentration, a product of microbial metabolism, was measured as a biomarker of leaky guts (Nielsen et al. 2012, Sanz Fernandez et al. 2014). As expected, D-lactate increased during HS, suggesting that the intestinal barrier function was compromised. In support of this, intestinal AP reduced due to chronic HS. In fact, intestinal AP plays important roles in LPS dephosphorylation, reduction of LPS-induced intestinal inflammation and restriction of bacterial translocation (Goldberg et al. 2008). Therefore, decrease in intestinal AP activity as a result of HS reduces intestinal capacity to detoxify LPS which in turn may lead to intestinal inflammation. Furthermore, HS decreased the thyroid hormone $\left(\mathrm{T}_{3}\right)$ level (Silva 2003) in the current study, which may result in the down-regulation of IAP in transcriptional level (Hodin et al. 1992), thus influencing intestinal barrier function.

Morphological changes in the small intestine were also observed. Desquamation of the mucosal epithelium and shortened height of intestinal villi and crypts indicates damage to the intestinal epithelium. This could lead to increased permeability (Lambert et al. 2002).

Therefore, chronic HS can reduce intestinal integrity and function. Herein, we extended our analysis to the proteomic response of porcine small intestines to chronic HS. Proteomics identified 53 proteins in small intestine that were affected by HS. These proteins are involved in stress response and defense, cell structure and motility, glucose and energy metabolism, antioxidant, cellular apoptosis, nutrient absorption and transport, and gene regulation. Results of the current study indicate, for the first time, mild-HS-induced alterations of the smallintestinal proteomes in finishing pigs.

\section{Stress response and defense}

We reported several stress response proteins, including heat shock proteins (HSPs; HSPH1, HSPA1A, HSPA5, HSPB1 and FKBP4), and acute phase proteins (APPs; HP, AHSG, RBP4 and ALB) that were changed by HS. Many of these are heat-inducible. HSPs are a family of proteins that restore protein homeostasis and contribute to cell survival. Therefore, they have various roles, which include chaperoning, aiding the removal of damaged proteins, protein folding and transport, inhibition of cellular apoptosis, and protection cells (including intestinal epithelial cells) against thermal or oxidative stress (Horowitz \& Robinson 2007). Noticeably, we found that HSPH1, HSPA1A and

Published by Bioscientifica Ltd 


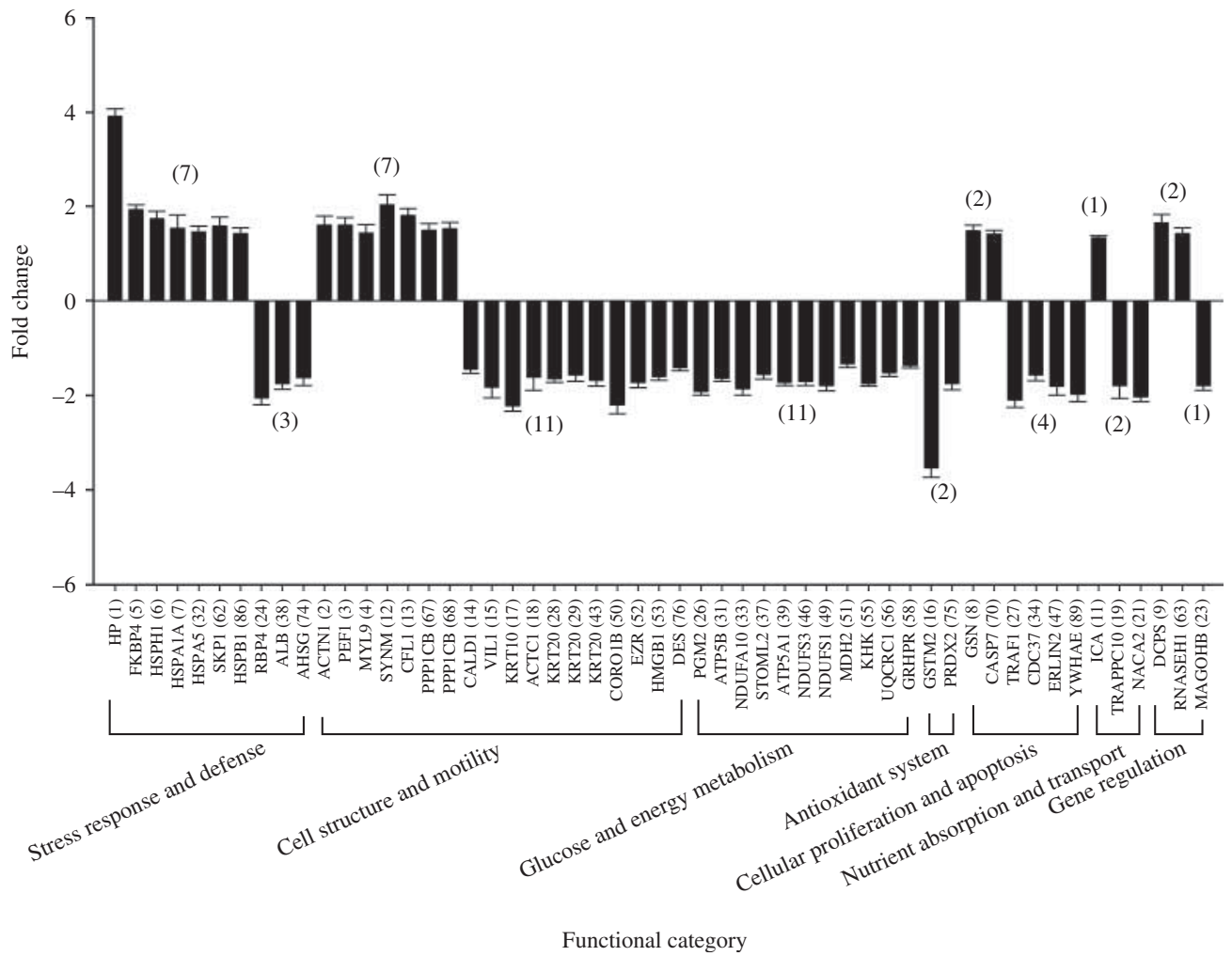

\section{Figure 4}

Quantitative analysis of the proteins of differential abundance from the jejunum mucosa of finishing pigs.

FKBP4 were associated and involved in the heat shock factor 1 (HSF1)-mediated heat shock response pathway. Considering these proteins functions and their interactions, overexpression of the stress response proteins may indicate their coordinating protection intestine from damage to chronic HS. These results are in agreement with recent reports in acute HS model for growing pigs (Pearce et al. 2013b), suggesting that chronic and acute HS commonly provoke heat shock response, resulting in changes in HSPs expression (Xie et al. 2014).

A novel and important finding of this study is that changes of APPs abundance were observed in jejunum of heat-stressed pigs. HP (haptoglobin), a known positively responding APP, increased 3.91-fold, coherent with report on dramatic increase of HP concentrations in HS pigs blood (Pearce et al. 2013a). It binds free hemoglobin and thus reduces the oxidative damage associated with hemolysis (Murata et al. 2004). Hp is synergistically enhanced by glucocorticoids (Baumann et al. 1989) and its secretion is increased during inflammatory reactions in pigs (Dobryszycka 1997). This result is consistent with increased plasma cortisol (a main glucocorticoid hormone) due to chronic HS in our previous study (Hao et al. 2014). In contrast, AHSG (known as fetuin), RBP4 and
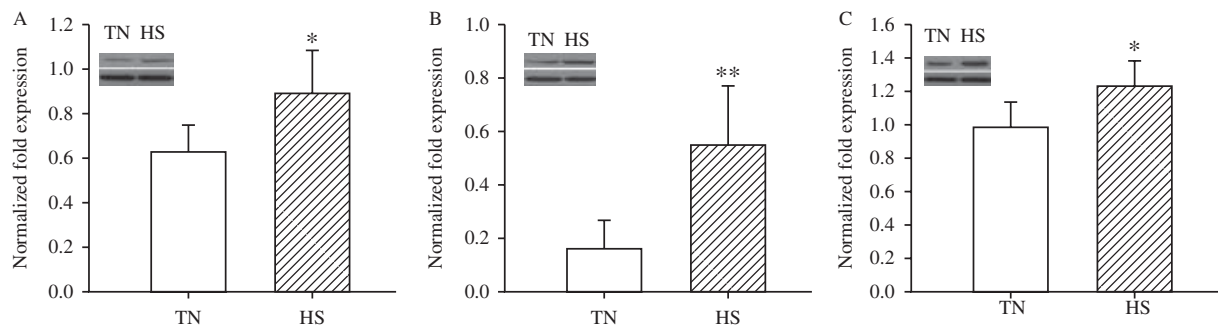

Figure 5

Western blotting analysis of jejunum mucosa proteins, HSPH1 (A), HSPB1 (B), and HSPA1A (C). Data are mean \pm s.D., $n=8$ pigs for each group. ${ }^{*} P<0.05$ and $* * P<0.01$ before vs after heat stress.

http://jme.endocrinology-journals.org DOI: 10.1530/JME-15-0161
(C) 2015 The authors Printed in Great Britain
Published by Bioscientifica Ltd. 


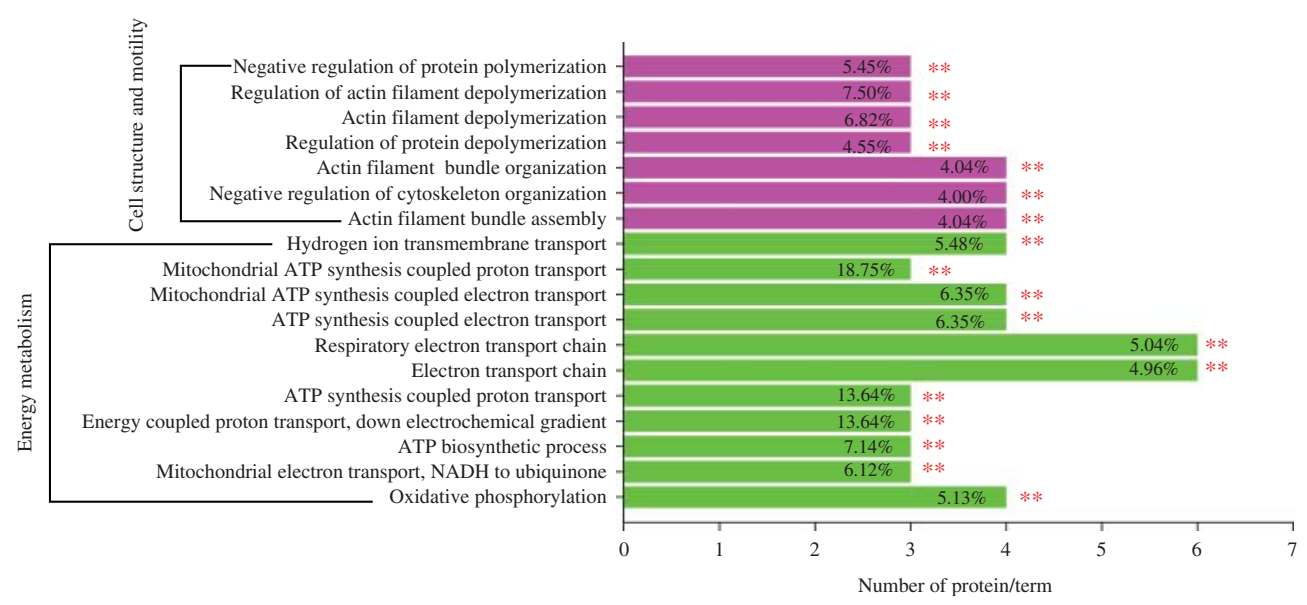

Figure 6

Functional enrichment analysis of the proteins of differential abundance from the jejunum mucosa of finishing pigs using the ClueGO software. $* \star P<0.01$.

ALB are considered negatively responding APPs and well characterized in humans (Ombrellino et al. 2001, Gruys et al. 2005) but not as much in pigs. APPs are considered non-specific innate immune components involved in the repair of tissue damage, the restraint of microbial growth, and the restoration of homeostasis. In response to chronic heat exposure, positively- and negatively-responding APPs showed an increase and decrease in levels respectively. Moreover, inflammation or tissue injury can trigger cytokine (e.g. TNF) release by defense-oriented cells including mucosal epithelium, thereby activating the acute phase protein response (Murata et al. 2004). Results above indicate that chronic HS may induce inflammation or damage to mucosal epithelium?either of which would trigger HSP and APP responses to counteract the negative effects of heat exposure.

\section{Cell structure and motility}

Cytoskeletal proteins have vital roles in the maturation, migration, and renewal of epithelial cells along the crypt- villus axis (Gordon \& Hermiston 1994). In the present study, the highest representation of identified differentially expressed proteins related to the cytoskeleton reflects the effect of HS on cell structure and motility. CFL1 is a protein, which directly regulates actin dynamics and depolymerization. MYL9 plays a critical role in cell motility and contraction. Decreased intestinal integrity has been correlated with cofilin dephosphorylation and MYL9 phosphorylation respectively. Interestingly, MYL9 phosphorylation is catalyzed by MLCK and MLC phosphatase (MLCP). The catalytic activity of MLCP is attributable to PPC1B (Grassie et al. 2011). The up-regulation of PPC1B in the present study may accelerate the MYL9 phosphorylation, consequently resulting in increased intestinal permeability. Our current results are consistent with previous studies as both proteins were increased due to HS in the ileum (Qi et al. 2011, Pearce et al. 2014b).

EZR (also known as villin 2; VIL2) and VIL1, which are microvillar proteins in intestinal epithelial cells, are required for cell surface adhesion, migration, and organization (Saleh et al. 2009), and are thereby involved in

Table 6 Enriched KEGG pathway-based sets of differentially expressed proteins in the intestine of finishing pigs during chronic heat stress ${ }^{a}$

\begin{tabular}{|c|c|c|c|c|}
\hline Pathway name & Count & Protein & $P$ value & q value \\
\hline Oxidative phosphorylation & 5 & ATP5A1, ATP5B, NDUFS3, NDUFA10, UQCRC1 & $5.9 \mathrm{E}-3$ & $9.6 \mathrm{E}-2$ \\
\hline Regulation of actin cytoskeleton & 6 & ACTN1, CFL1, EZR, MYL9, PPP1CB, GSN & $6.7 \mathrm{E}-3$ & $8.2 \mathrm{E}-2$ \\
\hline
\end{tabular}

ATP5A1, ATP synthase subunit alpha, mitochondrial; ATP5B, ATP synthase subunit beta, mitochondrial; NDUFS3, NADH-coenzyme Q reductase; NDUFA10, NADH dehydrogenase (ubiquinone) 1 alpha subcomplex subunit 10, mitochondrial; UQCRC1(cytochrome b-c1 complex subunit 1, mitochondrial; ACTN1, alpha-actinin-1; CFL1, cofilin-1, EZR, ezrin; MYL9, myosin regulatory light chain, LC20; PPP1CB, serine/threonine-protein phosphatase PP1-beta catalytic; GSN, gelsolin.

${ }^{a}$ The number of count refers to the amount of proteins involved in the extended KEGG network and pathway. $P$ values are calculated according to a hypergeometric test, $q$ values represent $P$ values corrected for multiple testing using the false discovery rate method.

http://jme.endocrinology-journals.org DOI: 10.1530/JME-15-0161 (c) 2015 The authors Printed in Great Britain
Published by Bioscientifica Ltd. 


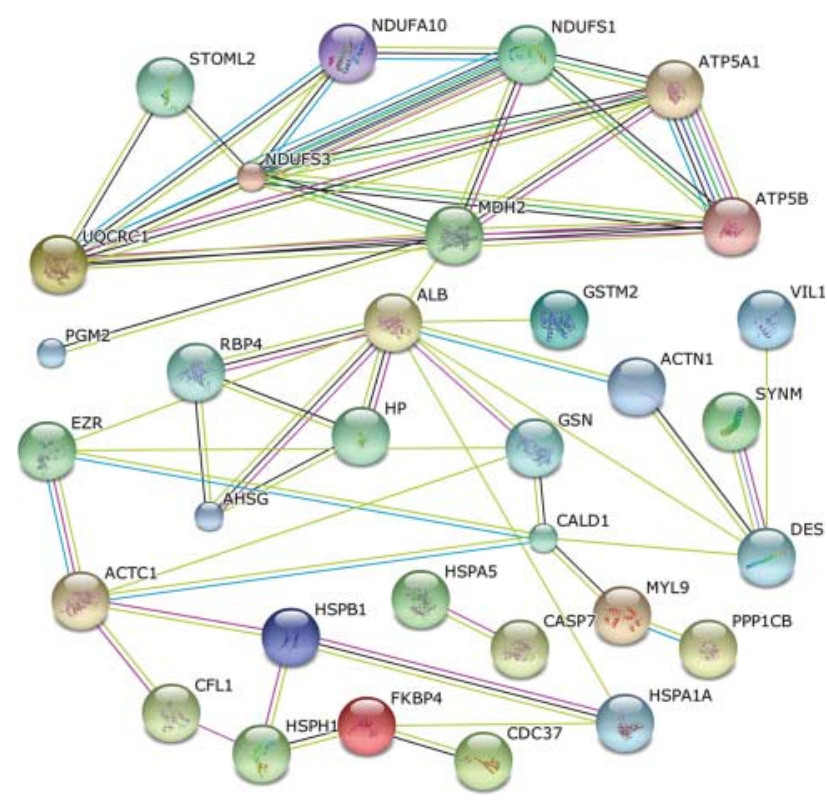

Figure 7

Biological interaction network of the identified differentially expressed proteins from the jejunum mucosa of finishing pigs. A red line, fusion evidence; a green line, neighborhood evidence; a blue line, co-occurrence evidence; a purple line, experimental evidence; a yellow line, text mining evidence; a light blue line, database evidence; and a black line, coexpression evidence.

intestinal absorption. In addition, KRT10 and KRT20 function in maintaining the cell structure as the major intermediate filament protein in the intestinal epithelia. CALD1 is a regulatory factor in the microfilament network and is thus involved in the assembly and stabilization of microfilaments in the apical portion of the intestinal epithelial cells (Ishimura et al. 1984). CORO1B is an actin binding protein, which regulates cell motility by coordinating actin filament turnover. Collectively, the up-regulation of CFL1 and MYL9 correlated with the down-regulation of EZR, VIL1, KRT10, KRT20, and CORO1B in heat-stressed pigs indicates orchestrated regulation of actin cytoskeletal dynamics and the negative impact of HS on intestinal integrity and TJ. This may be supported by the result of increased epithelial sloughing or atrophy of their intestinal villus.

\section{Glucose and energy metabolism}

The gastrointestinal tract is a metabolically active organ consuming considerable amounts of energy (Cant et al. 1996). An important finding of this study was that HS affected expression of key enzymes involved in intestinal glucose and energy metabolism, including PGM2, MDH2, NDUFA10, NDUFS3, NDUFS, ATP5A1 and ATP5B. PGM2 and $\mathrm{MDH} 2$ were involved in glycolysis and the citric acid cycle, respectively, both of which were down-regulated under HS. These results indicate that HS slows down energy metabolism.

Another mechanism involved in energy supply is the electron transport chain (ETC) and ATP generation via oxidative phosphorylation (Fig. 8). NDUFA10, NDUFS3

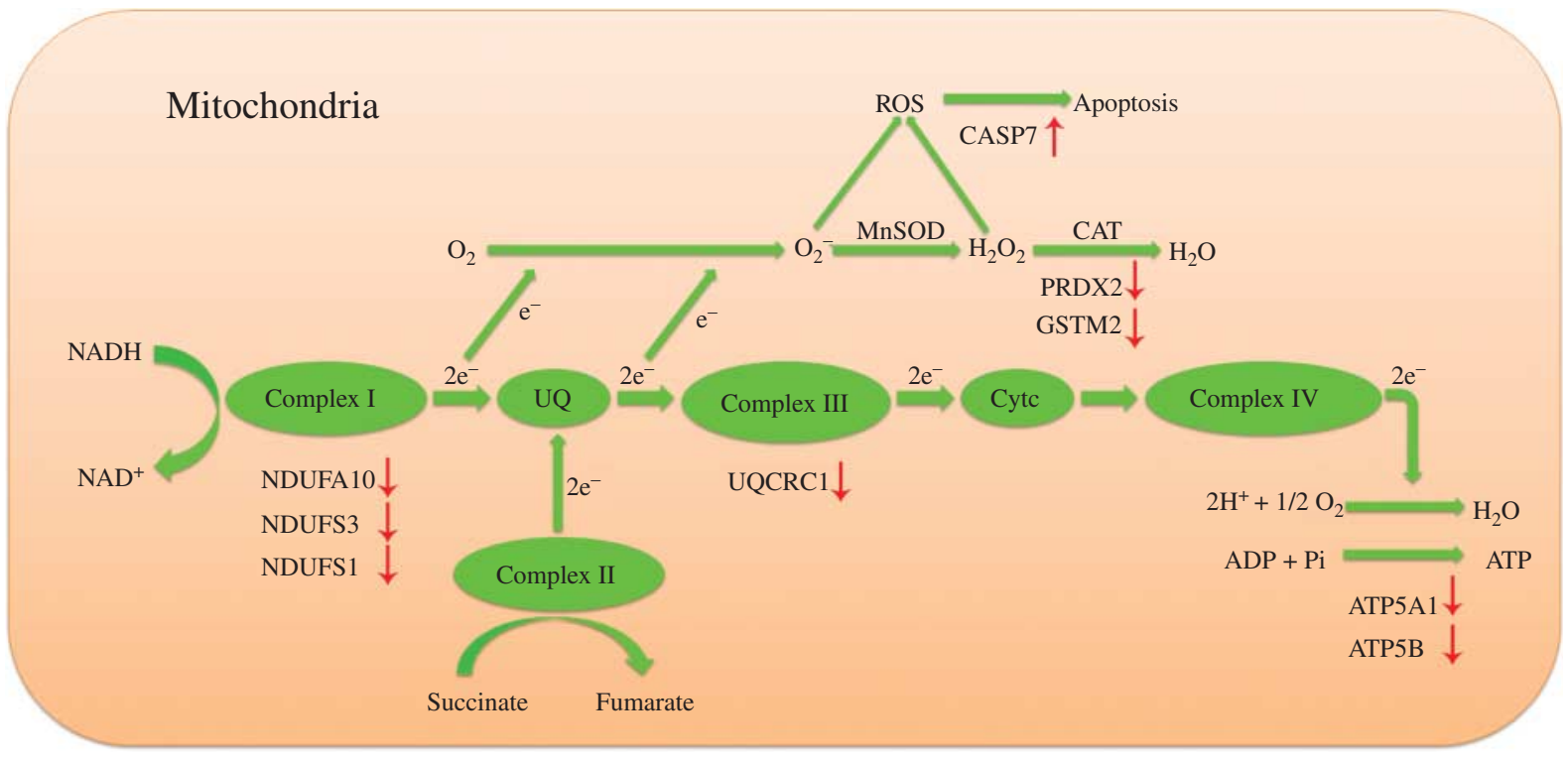

Figure 8

Differentially expressed proteins involved in electron transport chain (ETC) and ATP generation. The red arrows indicate up- or down-regulated proteins in response to the chronic heat stress. Protein names for the symbols used are defined in Table 4.

http://jme.endocrinology-journals.org DOI: $10.1530 / \mathrm{JME}-15-0161$
(C) 2015 The authors Printed in Great Britain
Published by Bioscientifica Ltd. 
and NDUFS1 are constituents of the mitochondrial electron transport chain complex I. UQCRC1 is an essential part of the mitochondrial electron transport chain complex III; all of these are responsible for pumping protons through the mitochondrial inner membrane. ATP5A1 and ATP5B, two subunits of the catalytic portion F1 of the ATP synthase complex, play a critical role in ATP generation. In the present study, heat-stressed pigs showed lower expression of ETC and ATP generation proteins. The energy derived from the passage of electrons through complexes I, III, and IV of the respiratory chain is coupled to the synthesis of ATP. Low abundance of these proteins suggests impairment in the electron transport system and ATP synthase complex, leading to compromised energy metabolism in the intestine of heat-stressed pigs. This observation is consistent with results from Weller et al. (2013), who revealed that genes involved in energy metabolism in muscle have reduced expression in HSed pigs. Moreover, previous research has proven that oxidative stress is related to the impairment of energy metabolism (Zaza et al. 2013). The electron transport chain of the mitochondria is a major source of cellular ROS. The depression of the respiratory chain by HS will lead to more formation of ROS, thus leading to cellular oxidative stress.

\section{Antioxidant system}

Another pathway that appeared to be affected by HS is the antioxidant system. PRDX2 belongs to the ubiquitous family of peroxiredoxins that protect cellular lipids and proteins against oxidative damage generated by reactive oxygen species (ROS) (Di Quinzio et al. 2007). GST is crucial in the glutathione redox cycle, and catalyzes the conjugation of glutathione to a variety of electrophiles including ROS in small intestines (Aw 2005). Furthermore, a previous study has shown that HS leads to decreased glutathione in the small intestine (Pearce et al. 2013a). Glutathione is required for the activity of GST and reduced availability of glutathione may have resulted in reduced GST expression in chronic HS pig intestine. Both proteins serve as scavengers of ROS in antioxidant defense. A decrease in both GSTM2 and PRDX2 during chronic HS suggests a reduced ability of small intestine to address ROS.

\section{Cellular apoptosis}

TRAF1, 14-3-3E (YWHAE), ERLIN2 and CASP7 participate in cellular apoptosis. TRAF1, which is a product of the NF-kB-responsive protein, can directly bind or block caspase- 8 activation and prevent TNF-induced apoptosis
(Chang \& Tepperman 2003). The 14-3-3E, an isoform of 14-3-3 proteins, attenuates c-Abl- and ADR-induced apoptosis. Decrease in both TRAF1 and 14-3-3E may accelerate apoptosis. In addition, down-regulation of ERLIN2 suppresses degradation of inositol 1,4,5-trisphosphate receptors, leading to pathological changes in $\mathrm{Ca}^{2+}$ signaling causing cellular apoptosis (Pearce et al. 2007). Furthermore, CASP7 belongs to the subgroup of executioner caspases and facilitates the execution of apoptosis (Lamkanfi \& Kanneganti 2010). Collectively, HS may induce intestinal epithelial cell apoptosis, which consequently compromises the intestinal epithelium barrier function.

In living cells, proteins build complex networks to fulfill these functions through protein-protein interactions, modifications, and protein regulation (Wang et al. 2011). The biological interaction network (BIN) clearly demonstrates that proteins related to cell structure and motility, energy metabolism and stress response and defense are the majority and account for approximately $56.6 \%$ of the BIN, which further ascertains molecular adaptive responses of the intestine during HS. These results are in line with the results of GO functional enrichment analysis.

\section{Conclusions}

This study integrates biochemical, histological and proteomic approaches to identify the effects of chronic HS on the intestines of finishing pigs. HS results in decreased intestinal integrity and function, which might be attributed to changes of intestinal structure proteins. The downregulation of proteins associated with the tricarboxylic acid cycle (TCA) cycle, ETC and oxidative phosphorylation suggests that chronic HS compromises energy metabolism and thus induces oxidative stress. Furthermore, in response to thermal and oxidative stress, the up-regulation of HSPs and alteration of APPs indicate formation of molecular adaptive mechanisms. The constructed BIN predicted that 28 proteins related to energy production, the cytoskeleton, stress response, and defense act as key nodes for energy metabolism, structure and immunity of the intestine. These advanced proteome data significantly expand our knowledge on effects of chronic HS on intestines.

\section{Declaration of interest}

The authors declare that there is no conflict of interest that could be perceived as prejudicing the impartiality of the research reported.

Published by Bioscientifica Ltd 


\section{Funding}

The investigation was financially supported by the Basic Research Program of China (2012CB124706), the Agricultural Science and Technology Innovation Program (ASTIP-IAS07) and Key Project in the National Science \& Technology Pillar Program (2012BAD39B0202).

\section{References}

Ashburner M, Ball CA, Blake JA, Botstein D, Butler H, Cherry JM, Davis AP, Dolinski K, Dwight SS \& Eppig JT 2000 Gene Ontology: tool for the unification of biology. Nature Genetics 25 25-29. (doi:10.1038/75556)

Aw TY 2005 Intestinal glutathione: determinant of mucosal peroxide transport, metabolism, and oxidative susceptibility. Toxicology and Applied Pharmacology 204 320-328. (doi:10.1016/j.taap.2004.11.016)

Barthe L, Woodley JF, Kenworthy S \& Houin G 1998 An improved everted gut sac as a simple and accurate technique to measure paracellular transport across the small intestine. European Journal of Drug Metabolism and Pharmacokinetics 23 313-323. (doi:10.1007/BF03189357)

Baumann H, Prowse K, Marinković S, Won KA \& Jahreis G 1989 Stimulation of hepatic acute phase response by cytokines and glucocorticoidsa. Annals of the New York Academy of Sciences $\mathbf{5 5 7}$ 280-296. (doi:10.1111/j.1749-6632.1989.tb24021.x)

Bindea G, Mlecnik B, Hackl H, Charoentong P, Tosolini M, Kirilovsky A, Fridman WH, Pagès F, Trajanoski Z \& Galon J 2009 ClueGO: a Cytoscape plug-in to decipher functionally grouped gene ontology and pathway annotation networks. Bioinformatics 25 1091-1093. (doi:10.1093/bioinformatics/btp101)

Cant JP, McBride BW \& Croom W 1996 The regulation of intestinal metabolism and its impact on whole animal energetics. Journal of Animal Science 74 2541-2553.

Chang Q \& Tepperman B 2003 Effect of selective PKC isoform activation and inhibition on TNF $\alpha$-induced injury and apoptosis in human intestinal epithelial cells. British Journal of Pharmacology 140 41-52. (doi:10.1038/sj.bjp.0705398)

Coffey RD, Parker GR \& Laurent KM 1995 Feeding growing-finishing pigs to maximize lean growth rate. ASC-147, Cooperative Extension Service. Lexington, KY, USA: University of Kentucky College of Agriculture.

Cruzen S, Boddicker R, Graves K, Johnson T, Arkfeld E, Baumgard L, Ross J, Safranski T, Lucy M \& Lonergan S 2015 Effects of long term heat stress in utero or during finishing on pork carcass composition. Meat Science 101 108. (doi:10.1016/j.meatsci.2014.09.026)

Dallaire S, Drolet R \& Brodeur D 1996 Sow mortality associated with high ambient temperatures. Canadian Veterinary Journal 37 237-239.

Di Quinzio MK, Oliva K, Holdsworth SJ, Ayhan M, Walker SP, Rice GE, Georgiou HM \& Permezel M 2007 Proteomic analysis and characterisation of human cervico-vaginal fluid proteins. Australian \& New Zealand Journal of Obstetrics \& Gynaecology 47 9-15. (doi:10.1111/ j.1479-828X.2006.00671.x)

Dobryszycka W 1997 Biological functions of haptoglobin-new pieces to an old puzzle. European Journal of Clinical Chemistry and Clinical Biochemistry 35 647-654.

Gabler NK, Spencer JD, Webel DM \& Spurlock ME 2007 In utero and postnatal exposure to long chain (n-3) PUFA enhances intestinal glucose absorption and energy stores in weanling pigs. Journal of Nutrition $1372351-2358$.

Goldberg RF, Austen WG, Xiaobo Z, Gitonga M, Golam M, Shaluk B, Michael MC, Eberlin KR, Nguyen JT \& Tatlidede HS 2008 Intestinal alkaline phosphatase is a gut mucosal defense factor maintained by enteral nutrition. PNAS 105 3551-3556. (doi:10.1073/pnas. 0712140105)

Gordon CJ 1993 Temperature acclimation. Temperature Regulation in Laboratory Rodents, pp 163-180. New York, NY: Cambridge University Press.
Gordon JI \& Hermiston ML 1994 Differentiation and self-renewal in the mouse gastrointestinal epithelium. Current Opinion in Cell Biology 6 795-803. (doi:10.1016/0955-0674(94)90047-7)

Grassie ME, Moffat LD, Walsh MP \& MacDonald JA 2011 The myosin phosphatase targeting protein (MYPT) family: a regulated mechanism for achieving substrate specificity of the catalytic subunit of protein phosphatase type $1 \delta$. Archives of Biochemistry and Biophysics $\mathbf{5 1 0}$ 147-159. (doi:10.1016/j.abb.2011.01.018)

Gruys E, Toussaint MJM, Niewold TA \& Koopmans SJ 2005 Review: Acute phase reaction and acute phase proteins. Journal of Zhejiang University. Science. B 6 1045-1056. (doi:10.1631/jzus.2005.B1045)

Hao Y, Feng Y, Yang P, Feng J, Lin H \& Gu X 2014 Nutritional and physiological responses of finishing pigs exposed to a permanent heat exposure during three weeks. Archives of Animal Nutrition 68 296-308. (doi:10.1080/1745039X.2014.931522)

Hirata Y, Broquet AH, Menchén L \& Kagnoff MF 2007 Activation of innate immune defense mechanisms by signaling through RIG-I/IPS-1 in intestinal epithelial cells. Journal of Immunology 179 5425-5432. (doi:10.4049/jimmunol.179.8.5425)

Hodin RA, Chamberlain SM \& Upton MP 1992 Thyroid hormone differentially regulates rat intestinal brush border enzyme gene expression. Gastroenterology 103 1529-1536.

Horowitz M 2002 From molecular and cellular to integrative heat defense during exposure to chronic heat. Comparative Biochemistry and Physiology. Part A, Molecular \& Integrative Physiology 131 475-483. (doi:10.1016/S1095-6433(01)00500-1)

Horowitz M \& Robinson SD 2007 Heat shock proteins and the heat shock response during hyperthermia and its modulation by altered physiological conditions. Progress in Brain Research 162 433-446.

Ishimura K, Fujita H, Ban T, Matsuda H, Sobne K \& Kakiuchi S 1984 Immunocytochemical demonstration of caldesmon (a calmodulinbinding, F-actin-interacting protein) in smooth muscle fibers and absorptive epithelial cells in the small intestine of the rat. Cell and Tissue Research 235 207-209. (doi:10.1007/BF00213742)

Kregel KC 2002 Invited review: heat shock proteins: modifying factors in physiological stress responses and acquired thermotolerance. Journal of Applied Physiology 92 2177-2186. (doi:10.1152/japplphysiol.01267. 2001)

Laganá C, Ribeiro AML, Kessler ADM, Kratz LR \& Pinheiro CC 2007 Effects of the reduction of dietary heat increment on the performance, carcass yield, and diet digestibility of broilers submitted to heat stress. Revista Brasileira de Ciência Avícola 9 45-51.

Lambert G 2009 Stress-induced gastrointestinal barrier dysfunction and its inflammatory effects. Journal of Animal Science 87 E101-E108. (doi:10.2527/jas.2008-1339)

Lambert GP, Gisolfi CV, Berg DJ, Moseley PL, Oberley LW \& Kregel KC 2002 Selected contribution: Hyperthermia-induced intestinal permeability and the role of oxidative and nitrosative stress. Journal of Applied Physiology 92 1750-1761. (doi:10.1152/japplphysiol. 00787.2001)

Lamkanfi M \& Kanneganti TD 2010 Caspase-7: A protease involved in apoptosis and inflammation. International Journal of Biochemistry \& Cell Biology 42 21-24. (doi:10.1016/j.biocel.2009.09.013)

Liu F, Yin J, Du M, Yan P, Xu J, Zhu X \& Yu J 2009 Heat-stress-induced damage to porcine small intestinal epithelium associated with downregulation of epithelial growth factor signaling. Journal of Animal Science 87 1941-1949. (doi:10.2527/jas.2008-1624)

Maier S, Pajk W, Ulmer H, Hausdorfer H, Torgersen C, Klocker J, Hasibeder W \& Knotzer H 2009 Epoprostenol improves mucosal tissue oxygen tension in an acute endotoxemic pig model. Shock 31 104-110. (doi:10.1097/SHK.0b013e31817c06ed)

Mohammed ME \& Johnson HD 1985 Effect of growth hormone on milk yields and related physiological functions of Holstein cows exposed to heat stress. Journal of Dairy Science 68 1123-1133. (doi:10.3168/jds. S0022-0302(85)80938-3) 
Morera P, Basiricò L, Hosoda K \& Bernabucci U 2012 Chronic heat stress up-regulates leptin and adiponectin secretion and expression and improves leptin, adiponectin and insulin sensitivity in mice. Journal of Molecular Endocrinology 48 129-138. (doi:10.1530/JME-11-0054)

Murata H, Shimada N \& Yoshioka M 2004 Current research on acute phase proteins in veterinary diagnosis: an overview. Veterinary Journal 168 28-40. (doi:10.1016/S1090-0233(03)00119-9)

Nielsen C, Mortensen FV, Erlandsen EJ \& Lindholt JS 2012 L- and D-lactate as biomarkers of arterial-induced intestinal ischemia: An experimental study in pigs. International Journal of Surgery 10 296-300. (doi:10.1016/ j.ijsu.2012.05.003)

Ombrellino M, Wang HC, Yang H, Zhang MH, Vishnubhakat J, Frazier A, Scher LA, Friedman SG \& Tracey KJ 2001 Fetuin, a negative acute phase protein, attenuates TNF synthesis and the innate inflammatory response to carrageenan. Shock 15 181-185. (doi:10.1097/00024382200115030-00004)

Pearce MMP, Wang Y, Kelley GG \& Wojcikiewicz RJH 2007 SPFH2 mediates the endoplasmic reticulum-associated degradation of inositol 1,4,5-trisphosphate receptors and other substrates in mammalian cells. Journal of Biological Chemistry 282 4-20115.

Pearce S, Mani V, Boddicker R, Johnson J, Weber T, Ross J, Baumgard L \& Gabler N 2012 Heat stress reduces barrier function and alters intestinal metabolism in growing pigs. Journal of Animal Science 90 257-259. (doi:10.2527/jas.52339)

Pearce S, Gabler N, Ross J, Escobar J, Patience J, Rhoads R \& Baumgard L $2013 a$ The effects of heat stress and plane of nutrition on metabolism in growing pigs. Journal of Animal Science 91 2108-2118. (doi:10.2527/jas. 2012-5738)

Pearce SC, Mani V, Boddicker RL, Johnson JS, Weber TE, Ross JW, Rhoads RP, Baumgard LH \& Gabler NK 2013 $b$ Heat stress reduces intestinal barrier integrity and favors intestinal glucose transport in growing pigs. PLOS ONE $\mathbf{8}$ e70215. (doi:10.1371/journal.pone.0070215)

Pearce SC, Sanz-Fernandez MV, Hollis JH, Baumgard LH \& Gabler NK 2014a Short-term exposure to heat stress attenuates appetite and intestinal integrity in growing pigs. Journal of Animal Science $925444-5454$. (doi:10.2527/jas.2014-8407)

Pearce S, Huff-Lonergan E, Lonergan S, Baumgard L \& Gabler N 2014b Heat stress and reduced feed intake alter the intestinal proteomic profile. FASEB Journal 28 241-246.

Pereira AMF, Baccari F, Titto EAL \& Almeida JAA 2008 Effect of thermal stress on physiological parameters, feed intake and plasma thyroid hormones concentration in Alentejana, Mertolenga, Frisian and Limousine cattle breeds. International Journal of Biometeorology $\mathbf{5 2}$ 199-208. (doi:10.1007/s00484-007-0111-x)

Qi H, Wang P, Liu C, Li M, Wang S, Huang Y \& Wang F 2011 Involvement of HIF- $1 \alpha$ in MLCK-dependent endothelial barrier dysfunction in hypoxia. Cellular Physiology and Biochemistry 27 251-262. (doi:10.1159/ 000327951)

Ramagli LS \& Rodriguez LV 1985 Quantitation of microgram amounts of protein in two dimensional polyacrylamide gel electrophoresis sample buffer. Electrophoresis 6 559-563. (doi:10.1002/elps.1150061109)

Saito R, Smoot ME, Ono K, Ruscheinski J, Wang PL, Lotia S, Pico AR, Bader GD \& Ideker T 2012 A travel guide to Cytoscape plugins. Nature Methods 9 1069-1076. (doi:10.1038/nmeth.2212)
Saleh HS, Merkel U, Geissler KJ, Sperka T, Sechi A, Breithaupt C \& Morrison H 2009 Properties of an ezrin mutant defective in F-actin binding. Journal of Molecular Biology 385 1015-1031. (doi:10.1016/j. jmb.2008.11.051)

Sanz Fernandez MV, Pearce SC, Mani V, Gabler NK, Metzger L, Patience JF, Rhoads RP \& Baumgard LH 2014 Effects of dairy products on intestinal integrity in heat-stressed pigs. Temperature 1 128-134. (doi:10.4161/ temp.29561)

Silva JE 2003 The thermogenic effect of thyroid hormone and its clinica implications. Annals of Internal Medicine 139 205-213. (doi:10.7326/ 0003-4819-139-3-200308050-00018)

St-Pierre N, Cobanov B \& Schnitkey G 2003 Economic losses from heat stress by US livestock industries. Journal of Dairy Science 86 E52-E77. (doi:10.3168/jds.S0022-0302(03)74040-5)

Szklarczyk D, Franceschini A, Kuhn M, Simonovic M, Roth A, Minguez P, Doerks T, Stark M, Muller J \& Bork P 2011 The STRING database in 2011: functional interaction networks of proteins, globally integrated and scored. Nucleic Acids Research 39 D561-D568. (doi:10.1093/nar/ gkq973)

Turner JR 2006 Molecular basis of epithelial barrier regulation: from basic mechanisms to clinical application. American Journal of Pathology 169 1901-1909. (doi:10.2353/ajpath.2006.060681)

Wang X, Gulbahce N \& Yu H 2011 Network-based methods for human disease gene prediction. Briefings in Functional Genomics 10 280-293. (doi:10.1093/bfgp/elr024)

Wang X, Wu W, Lin G, Li D, Wu G \& Wang J 2009 Temporal proteomic analysis reveals continuous impairment of intestinal development in neonatal piglets with intrauterine growth restriction. Journal of Proteome Research 9 924-935. (doi:10.1021/pr900747d)

Wang X, Qiao S, Yin Y, Yue L, Wang Z \& Wu G 2007 A deficiency or excess of dietary threonine reduces protein synthesis in jejunum and skeletal muscle of young pigs. Journal of Nutrition 137 1442-1446.

Weller M, Alebrante L, Campos P, Saraiva A, Silva B, Donzele J, Oliveira R, Silva F, Gasparino E \& Lopes P 2013 Effect of heat stress and feeding phosphorus levels on pig electron transport chain gene expression. Animal 7 1985-1993. (doi:10.1017/S1751731113001535)

Xie J, Tang L, Lu L, Zhang L, Xi L, Liu HC, Odle J \& Luo X 2014 Differential expression of heat shock transcription factors and heat shock proteins after acute and chronic heat stress in laying chickens (Gallus gallus). PLOS ONE 9 e102204. (doi:10.1371/journal.pone. 0102204)

Xiong J, Yang Q, Kang J, Sun Y, Zhang T, Margaret G \& Ding W 2011 Simultaneous isolation of DNA, RNA, and protein from Medicago truncatula L. Electrophoresis 32 321-330. (doi:10.1002/elps. 201000425)

Yu J, Yin P, Liu F, Cheng G, Guo K, Lu A, Zhu Z, Luan W \& Xu J 2010 Effect of heat stress on the porcine small intestine: a morphological and gene expression study. Comparative Biochemistry and Physiology. Part A, Molecular \& Integrative Physiology 156 119-128. (doi:10.1016/j.cbpa 2010.01.008)

Zaza G, Granata S, Masola V, Rugiu C, Fantin F, Gesualdo L, Schena FP \& Lupo A 2013 Downregulation of Nuclear-Encoded Genes of Oxidative Metabolism in Dialyzed Chronic Kidney Disease Patients. PLoS ONE 8 e77847. (doi:10.1371/journal.pone.0077847)

Received in final form 26 August 2015

Accepted 28 September 2015

Accepted Preprint published online 28 September 2015 http://jme.endocrinology-journals.org

DOI: 10.1530/JME-15-0161
(C) 2015 The authors Printed in Great Britain
Published by Bioscientifica Ltd. 